\title{
Modes and Regulation of Endocytic Membrane Retrieval in Mouse Auditory Hair Cells
}

\author{
Jakob Neef, ${ }^{1,4}$ SangYong Jung, ${ }^{1,4}$ Aaron B. Wong, ${ }^{1,4,5}$ Kirsten Reuter, ${ }^{1}$ Tina Pangršič ${ }^{1,4}$ Rituparna Chakrabarti, ${ }^{2,4}$ \\ Sebastian Kügler ${ }^{3,6}$ Christine Lenz, ${ }^{1}$ Régis Nouvian, ${ }^{1}$ Rebecca M. Boumil, ${ }^{8}$ Wayne N. Frankel, ${ }^{8}$ Carolin Wichmann, ${ }^{2,4}$ \\ and Tobias Moser ${ }^{1,4,5,6,7}$ \\ ${ }^{1}$ InnerEarLab, Department of Otolaryngology, ${ }^{2}$ Molecular Architecture of Synapses Group, InnerEarLab, Department of Otolaryngology, and ${ }^{3}$ Department \\ of Neurology, University Medical Center Göttingen, D-37099 Göttingen, Germany, ${ }^{4}$ Collaborative Research Center 889, ${ }^{5}$ International Max Planck Research \\ Schools, Neuroscience, Göttingen Graduate School for Neuroscience, Biophysics, and Molecular Biosciences, ${ }^{6}$ Research Center for Nanoscale Microscopy \\ and Molecular Physiology of the Brain, and 7Bernstein Focus for Neurotechnology, University of Göttingen, D-37073 Göttingen, Germany, and ${ }^{8}$ The Jackson \\ Laboratory, Bar Harbor, Maine 04609
}

Synaptic vesicle recycling sustains high rates of neurotransmission at the ribbon-type active zones (AZs) of mouse auditory inner hair cells (IHCs), but its modes and molecular regulation are poorly understood. Electron microscopy indicated the presence of clathrinmediated endocytosis (CME) and bulk endocytosis. The endocytic proteins dynamin, clathrin, and amphiphysin are expressed and broadly distributed in IHCs. We used confocal vglut1-pHluorin imaging and membrane capacitance $\left(C_{\mathrm{m}}\right)$ measurements to study the spatial organization and dynamics of IHC exocytosis and endocytosis. Viral gene transfer expressed vglut1-pHluorin in IHCs and targeted it to synaptic vesicles. The intravesicular $\mathrm{pH}$ was $\sim 6.5$, supporting only a modest increase of vglut1-pHluorin fluorescence during exocytosis and $\mathrm{pH}$ neutralization. $\mathrm{Ca}^{2+}$ influx triggered an exocytic increase of vglut $1-\mathrm{pHluorin}$ fluorescence at the $\mathrm{AZs}$, around which it remained for several seconds. The endocytic $C_{\mathrm{m}}$ decline proceeded with constant rate (linear component) after exocytosis of the readily releasable pool (RRP). When exocytosis exceeded three to four RRP equivalents, IHCs additionally recruited a faster $C_{\mathrm{m}}$ decline (exponential component) that increased with the amount of preceding exocytosis and likely reflects bulk endocytosis. The dynamin inhibitor Dyngo-4a and the clathrin blocker pitstop 2 selectively impaired the linear component of endocytic $C_{\mathrm{m}}$ decline. A missense mutation of dynamin 1 ( $f i t f u l$ ) inhibited endocytosis to a similar extent as Dyngo-4a. We propose that IHCs use dynamin-dependent endocytosis via CME to support vesicle cycling during mild stimulation but recruit bulk endocytosis to balance massive exocytosis.

Key words: clathrin; dynamin; endocytosis; hearing; inner hair cell; pHluorin

\section{Introduction}

Sound encoding by inner hair cell (IHC) ribbon synapses is a fundamental step in hearing. Each of the active zones (AZs) of an IHC is thought to drive firing in a spiral ganglion neuron at rates of hundreds of Hertz during continued strong acoustic stimulation (for review, see Glowatzki et al., 2008; Meyer and Moser,

Received Aug. 1, 2013; revised 0ct. 22, 2013; accepted Nov. 6, 2013.

Author contributions: J.N. and T.M. designed research; J.N., S.J., A.B.W., K.R., T.P., R.C., C.L., R.N., and C.W. performed research;S.K., R.M.B., and W.N.F. contributed unpublished reagents/analytic tools; J.N., A.B.W., and T.P. analyzed data; J.N. and T.M. wrote the paper.

This work was supported by grants from the German Research Foundation through Collaborative Research Center 889 (Project A5 to T.M. and A7 to C.W.), the Center for Nanoscale Microscopy and Molecular Physiology of the Brain (T.M., S.K.), and the German Federal Ministry of Education and Research (through the Bernstein Focus for Neutotechnology Grant 01GQ0810 to T.M.). A.B.W. was supported by a Lichtenberg fellowship from the state of Lower Saxony (through the "Neurosenses" PhD program). We thank S. Gerke and C. Senger-Freitag for expert technical assistance. We also thank J. Daniel and P. Robinson for supplying us with Dyngo-8a. We thank J. Daniel and S. Rizzoli for feedback on this manuscript.

The authors declare no competing financial interests.

This article is freely available online through the $J$ Neurosci Author Open Choice option.

Correspondence should be addressed to either Jakob Neef or Tobias Moser, InnerEarLab, Department of Otolaryngology and Collaborative Research Center 889, University Medical Center Göttingen, D-37099 Göttingen, Germany. E-mail: jneef@gwdg.de or tmoser@gwdg.de.

DOI:10.1523/JNEUROSCI.3313-13.2014

Copyright $\odot 2014$ the authors $\quad 0270-6474 / 14 / 330705-12 \$ 15.00 / 0$
2010; Pangršič et al., 2012). This indefatigable signaling is accomplished through fast otoferlin-dependent replenishment of the readily releasable pool (RRP) (Pangršič et al., 2010; Levic et al., 2011), "non-inactivating" synaptic $\mathrm{Ca}^{2+}$ influx (Moser and Beutner, 2000; Schnee and Ricci, 2003; Yang et al., 2006; Cui et al., 2007), and efficient postsynaptic spike generation (Siegel, 1992; Rutherford et al., 2012). Fusion of vesicles at high rates is balanced by endocytosis, likely starting with lateral clearance of vesicular proteins and lipids from the AZ (for review, see Neher and Sakaba, 2008), which may involve an otoferlin-adaptor protein 2 interaction in IHCs (Duncker et al., 2013), followed by their endocytic retrieval from the plasma membrane (Parsons et al., 1994; Moser and Beutner, 2000; Beutner et al., 2001; Lenzi et al., 2002) and subsequent synaptic vesicle recycling (Siegel and Brownell, 1986; Griesinger et al., 2005). Two kinetically distinct types of endocytic retrieval-rapid (300 ms time constant) and slow (10-20 s time constant) — have been described for IHCs (Moser and Beutner, 2000; Beutner et al., 2001). Slow endocytosis has also been described in frog auditory hair cells, in which the time constant of retrieval seemed to scale with the amount of exocytosed vesicles (Cho et al., 2011). Rapid endocytosis in IHCs was elicited by $\mathrm{Ca}^{2+}$ uncaging, when cytosolic $\left[\mathrm{Ca}^{2+}\right]$ reached at least 
$15 \mu \mathrm{M}$, and increasingly contributed to retrieval when $\left[\mathrm{Ca}^{2+}\right]$ was further elevated. Which modes of endocytosis- "kiss-and-run" endocytosis, clathrin-mediated endocytosis (CME), or bulk endocytosis (for review, see $\mathrm{Wu}, 2004,2007$; Smith et al., 2008; Clayton and Cousin, 2009; Dittman and Ryan, 2009; Royle and Lagnado, 2010; Ferguson and De Camilli, 2012)—underlie these two types of membrane retrieval in IHCs remained unclear.

Little is known about the molecular regulation of hair cell endocytosis (Trapani et al., 2009; Boumil et al., 2010). In fitful mice, carrying a dynamin 1 missense mutation that interferes with dynamin 1 dimerization and function (Boumil et al., 2010), a subtle hearing impairment was found. It remained unclear whether this can be attributed to defective IHC endocytosis and whether dynamins 2 or 3 could partially compensate for the loss of dynamin 1 function. Moreover, although clathrin-coated pits and clathrin-coated vesicles can be found at the synaptic pole of IHCs (Siegel and Brownell, 1986; Sendin et al., 2007; Frank et al., 2010), the importance of CME for IHC endocytosis has not been tested yet. Finally, the spatial organization of endocytosis remained to be investigated. Here, we studied the molecular physiology of IHC endocytosis using electron microscopy, immunohistochemistry, vglut1-pHluorin imaging, patch-clamp membrane capacitance $\left(C_{\mathrm{m}}\right)$ recordings, $\mathrm{Ca}^{2+}$ uncaging, dynamin 1 mouse mutants, and pharmacological interference with dynamin and clathrin function.

\section{Materials and Methods}

Animals. Littermate Dyn $1^{f t f l / f t l}, D y n 1^{f t f l /+}$, and $D y n 1^{+/+}$mice (Boumil et al., 2010) were compared for a genetic approach to dynamin function. C57BL/6/J mice were used for experiments using pharmacological intervention with endocytic processes and flash photolysis of caged $\mathrm{Ca}^{2+}$. CD1 mice were used for vglut1-pHluorin imaging. Otof ${ }^{-1-}$ and $\mathrm{Otof}^{+/+}$mice (Roux et al., 2006; Reisinger et al., 2011) were used for flash photolysis of caged $\mathrm{Ca}^{2+}$. All mice were of either sex and examined at the age of 2-3 weeks. All experiments complied with national animal care guidelines and were approved by the University of Göttingen board for animal welfare and the animal welfare office of the state of Lower Saxony.

Immunohistochemistry and confocal microscopy of immunolabeled IHCs. Freshly dissected apical cochlear turns were fixed with $4 \%$ formaldehyde in PBS for $1 \mathrm{~h}$ on ice. Thereafter, the tissue was washed three times for $10 \mathrm{~min}$ in PBS and incubated for $1 \mathrm{~h}$ in goat serum dilution buffer (GSDB: 16\% normal goat serum, $450 \mathrm{~mm} \mathrm{NaCl}, 0.3 \%$ Triton X-100, and $20 \mathrm{~mm}$ phosphate buffer, $\mathrm{pH}$ 7.4) in a wet chamber at room temperature. Primary antibodies were dissolved in GSDB and applied overnight at $+4^{\circ} \mathrm{C}$ in a wet chamber. After washing three times for $10 \mathrm{~min}$ (wash buffer: $450 \mathrm{~mm} \mathrm{NaCl}, 20 \mathrm{~mm}$ phosphate buffer, and 0.3\% Triton X-100), the tissue was incubated with secondary antibodies in GSDB in a lightprotected wet chamber for $1 \mathrm{~h}$ at room temperature. Then the preparations were washed three times for $10 \mathrm{~min}$ in wash buffer and once for $10 \mathrm{~min}$ in $5 \mathrm{~mm}$ phosphate buffer, placed onto glass microscope slides with a drop of fluorescence mounting medium (Mowiol or 2,2thiodiethanol), and covered with thin glass coverslips. The following antibodies were used: mouse IgG1 anti-CtBP2 (also recognizing the ribbon protein ribeye; 1:200; BD Biosciences), mouse anti-otoferlin (1:500; Abcam), mouse anti-clathrin light chain (1:1000; specific for the neuronal splice variants; Synaptic Systems), mouse anti-dynamin 1/2/3 (1:200; BD Biosciences), rabbit anti-clathrin heavy chain (1:400; Biozol), rabbit anti-dynamin 1 (1:200; Synaptic Systems), rabbit anti-dynamin 3 (1: 1000; Synaptic Systems), rabbit anti-calbindin D-28k (1:1000; Swant), rabbit anti-amphiphysin (1:400; Synaptic Systems), rabbit anti-vglut3 (1:500; Synaptic Systems), guinea pig anti-vglut1 (1:1000; Synaptic Systems), and secondary Alexa Fluor 488-, Alexa Fluor 568-, and Alexa Fluor 633-labeled goat anti-mouse, anti-guinea pig, and anti-rabbit antibodies (1:200; Invitrogen). Confocal images were acquired using a laser scanning confocal microscope (Leica TCS SP2 or SP5; Leica Microsystems) with $488 \mathrm{~nm}$ (argon), $561 \mathrm{~nm}$ (helium-neon), and $633 \mathrm{~nm}$ (helium- neon) lasers for excitation and a $63 \times$ oil-immersion objective [1.4 numerical aperture (NA); Leica]. Images were processed using NIH ImageJ and assembled for display in Adobe Illustrator software.

Electron microscopy. Apical turns of the organ of Corti were prepared and either stimulated for $2 \mathrm{~min}$ at $36^{\circ} \mathrm{C}$ with a solution (in mM: $40 \mathrm{KCl}$, $108 \mathrm{NaCl}, 1 \mathrm{MgCl}_{2}, 1.3 \mathrm{CaCl}_{2}$, and $10 \mathrm{HEPES}$ ) and subsequently fixed for $1 \mathrm{~h}$ on ice with $4 \%$ PFA and $0.5 \%$ glutaraldehyde in $1 \times \mathrm{PBS}, \mathrm{pH} 7.2$, or immediately fixed for $1 \mathrm{~h}$ on ice with the same fixative. Subsequently, samples were fixed overnight on ice with secondary fixative comprising $2 \%$ glutaraldehyde in $0.1 \mathrm{~m}$ sodium cacodylate buffer, $\mathrm{pH}$ 7.2. The samples were washed in sodium cacodylate buffer and postfixed on ice for $1 \mathrm{~h}$ with $1 \%$ osmium tetroxide $(\mathrm{v} / \mathrm{v})$ in $0.1 \mathrm{~m}$ sodium cacodylate buffer, followed by a $1 \mathrm{~h}$ washing step in sodium cacodylate buffer and three brief washing steps in distilled water. The samples were stained en bloc with $1 \%(\mathrm{v} / \mathrm{v})$ uranyl acetate in distilled water for $1 \mathrm{~h}$ on ice. After a brief wash with distilled water, samples were dehydrated at room temperature in increasing ethanol concentrations, infiltrated in Epon resin $[100 \%$ EtOH/Epon 1:1 (v/v), 30 and 90 min; 100\% Epon, overnight], and embedded for $48 \mathrm{~h}$ at $70^{\circ} \mathrm{C}$. After conventional embedding, $65-75 \mathrm{~nm}$ sections were obtained approaching from the anterior edge using an Ultracut E (Reichert-Jung). Sections were postfixed and stained with uranyl acetate/lead citrate following standard protocols. Micrographs were taken with a JEOL electron microscope (JEM 1011) equipped with a Gatan Orius 1200A camera using the Digital Micrograph software package at an 8000-fold magnification. The diameter of clathrin-coated and synaptic vesicles was measured between the inner membrane boundaries. The diameter $(d)$ of clathrin-coated pits was determined by measuring the circumference $(C)$ of the inner leaflet of the membrane and calculated using $d=C / \pi$.

Expression of vglut1-pHluorin in IHCs. Complementary DNA of pHluorin-coupled VGLUT1 (kindly provided by Robert Edwards, University of California, San Francisco, San Francisco, CA) was subcloned into adeno-associated virus (AAV)- human beta actin promoter-eGFPwoodchuck posttranscriptional regulatory element-bovine growth hormone vector using an EcoRI and a HindIII restriction site introduced through PCR. Virus was produced as described previously (Kügler et al., 2007), using capsid proteins of serotype 1 and 2 (AAV1/2). IHCs were transduced by transuterine injection of otocysts in pregnant CD1 dams at postcoital day 11.5 (Bedrosian et al., 2006; Brigande et al., 2009; Reisinger et al., 2011).

Patch-clamp, flash photolysis of caged $\mathrm{Ca}^{2+}$, and confocal pHluorin imaging of IHCs. IHCs from apical coils of freshly dissected organs of Corti were patch clamped at room temperature $\left(22-24^{\circ} \mathrm{C}\right)$ as described previously (Moser and Beutner, 2000). For recordings of $\mathrm{Ca}^{2+}$ current and exocytosis, the pipette solution contained the following: $130 \mathrm{mM} \mathrm{Cs}$ gluconate, $10 \mathrm{~mm}$ tetraethylammonium (TEA)-Cl, $10 \mathrm{~mm}$ 4-AP, $10 \mathrm{~mm}$ HEPES, $1 \mathrm{mM} \mathrm{MgCl}_{2}$, and $300 \mu \mathrm{g} / \mathrm{ml}$ amphotericin B (for perforatedpatch recordings), $\mathrm{pH}$ 7.2. For ruptured patch recordings, 2 mM Mg-ATP and $0.3 \mathrm{~mm} \mathrm{Na-GTP}$ (in all experiments but a subset displayed in Fig. 6) were added to the solution, as well as $30 \mu \mathrm{M}$ of either Dyngo-4a (for pharmacological intervention with dynamin-mediated endocytosis; Howes et al., 2010; purchased from Tocris Bioscience) or Dyngo-8a (as a negative control; Daniel et al., 2012; kindly provided by Dr. Phillip Robinson, Children's Medical Research Institute, Westmead, Australia) or Pitstop 2 (for pharmacological intervention with CME). For experiments using GTP $\gamma$ S, the GTP in the intracellular solution was replaced by 0.3 mM GTP $\gamma \mathrm{S}$ (Tocris Biosciences or Sigma-Aldrich). The extracellular solution contained the following (in $\mathrm{mM}$ ): $99 \mathrm{NaCl}, 35 \mathrm{TEA}-\mathrm{Cl}, 2.8 \mathrm{KCl}, 2$ or $5 \mathrm{CaCl}_{2}, 1 \mathrm{MgCl}_{2}, 54$-AP, $1 \mathrm{CsCl}, 10$ HEPES, and 11.3 D-glucose, $\mathrm{pH}$ 7.2. For pHluorin imaging, the intracellular solution contained the following (in mM): 131.5 Cs-glutamate, 13 TEA-Cl, 20 CsOH-HEPES, $1 \mathrm{MgCl}_{2}, 2 \mathrm{MgATP}, 0.3 \mathrm{NaGTP}, 0.5$ EGTA, and 0.04 dimeric carboxytetramethylrhodamine-conjugated ribeye-binding peptide (Francis et al., 2011). The extracellular solution contained the following (in $\mathrm{mm}$ ): 104 $\mathrm{NaCl}, 35 \mathrm{TEA}-\mathrm{Cl}, 2.8 \mathrm{KCl}, 5 \mathrm{CaCl}_{2}, 1 \mathrm{MgCl}_{2}, 10 \mathrm{NaOH}-\mathrm{HEPES}$, and 11.3 D-glucose, $\mathrm{pH}$ 7.3. Flash photolysis of caged $\mathrm{Ca}^{2+}$ was performed as described previously (Beutner et al., 2001; Roux et al., 2006; Pangršič et al., 2010), and some of the responses were taken from previous work (Roux et al., 2006; Pangršič et al., 2010), in which endocytosis was not 

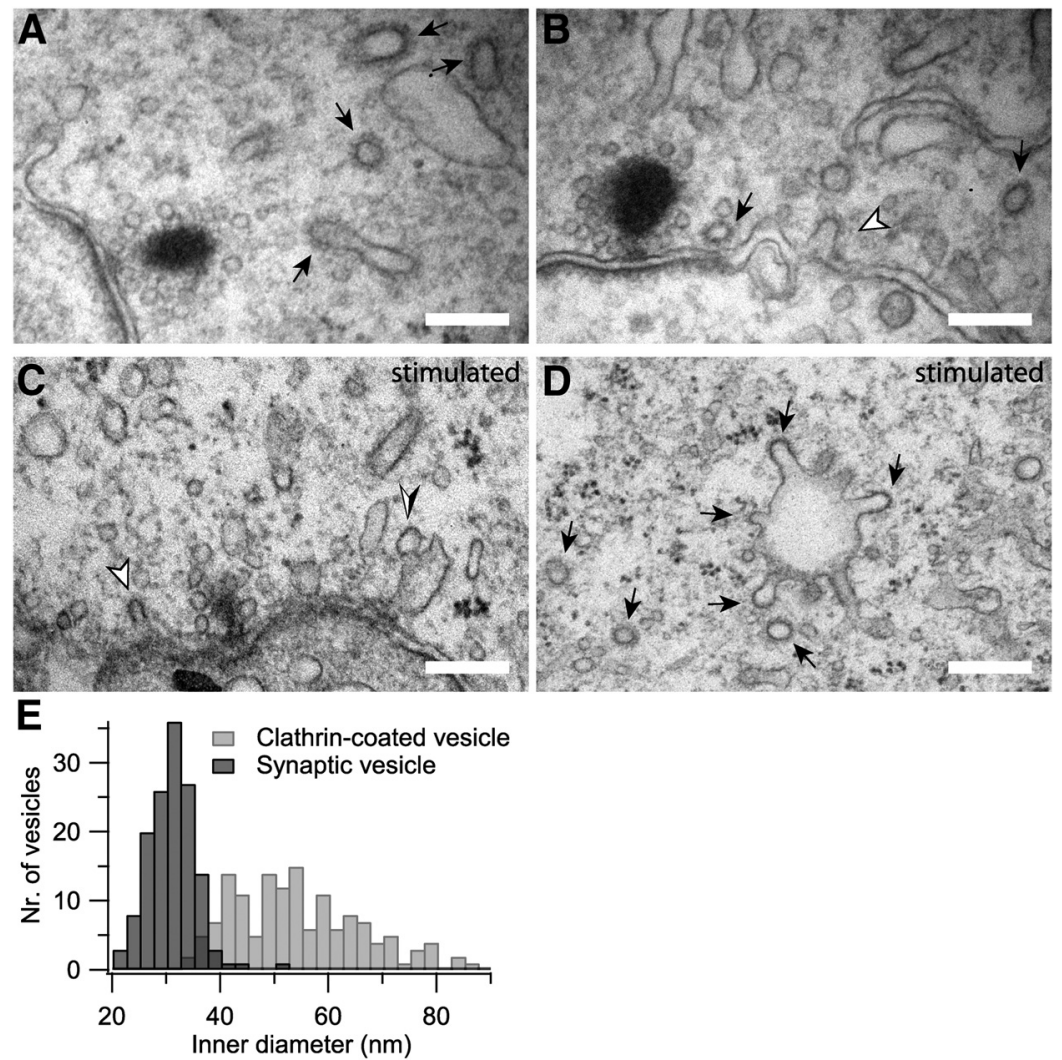

Figure 1. Clathrin-coated organelles and endocytic cisternae in IHCS. A-D, Representative electron micrographs of unstimulated $(\boldsymbol{A}, \boldsymbol{B})$ or high- $\mathrm{K}^{+}$-stimulated $(\boldsymbol{C}, \boldsymbol{D})$ IHC synapses illustrating the abundance of coated vesicles and cisternal membrane organelles as indications for CME and bulk endocytosis. White arrowheads point to coated pits forming at the plasma membrane $(\boldsymbol{B}, \boldsymbol{C})$; black arrows show examples of clathrin coats found on small vesicles or on cisternae in the perisynaptic cytoplasm $(\boldsymbol{A}-\boldsymbol{D})$. The black/white arrowhead indicates a large cistern that was still connected to the plasma membrane. D shows clathrin-coated pits emerging from a large cistern in the cytosol. Scale bars, $200 \mathrm{~nm}$. E, Histogram of the inner diameters of synaptic vesicles (dark gray) and clathrin-coated vesicles (light gray) found in the proximity of synaptic ribbons.

quantified. EPC-9 amplifiers (HEKA) controlled by Pulse or Patchmaster software (HEKA) were used for measurements. All voltages were corrected for liquid junction potentials. Currents were leak corrected using a p/10 protocol.

For $C_{\mathrm{m}}$ measurements, IHCs were stimulated by depolarizations of different durations to $-14 \mathrm{mV}$ at intervals of $60-120 \mathrm{~s}$. We measured $C_{\mathrm{m}}$ changes $\left(\Delta C_{\mathrm{m}}\right)$ using the Lindau-Neher technique (Lindau and Neher, 1988 ) as described previously (Moser and Beutner, 2000). The exocytic $\Delta C_{\mathrm{m}}$ was quantified as the difference of the averaged $C_{\mathrm{m}} 400 \mathrm{~ms}$ before and after (skipping the first $100 \mathrm{~ms}$ ) the depolarization. Mean $\Delta C_{\mathrm{m}}$ and $\mathrm{Ca}^{2+}$ charge estimates present grand averages calculated from the mean estimates of individual IHCs. This avoided dominance of IHCs contributing more sweeps. The endocytic decrease of $C_{\mathrm{m}}$ after a depolarizationinduced exocytic $\Delta C_{\mathrm{m}}$ was measured over $20 \mathrm{~s}$ after a 2-s-long recording of $C_{\mathrm{m}}$ baseline and 20,200, or $1000 \mathrm{~ms}$ of depolarization. Analysis of the linear component of endocytosis after brief depolarizations $(20 \mathrm{~ms})$ was performed by fitting a linear function to the postdepolarization $C_{\mathrm{m}}$ data, skipping the first $200 \mathrm{~ms}$, and noting the point at which the line fit returned to baseline $C_{\mathrm{m}}$. Recordings that did not return to baseline within $80 \mathrm{~s}$ were excluded from this analysis. We analyzed the exponential component of $C_{\mathrm{m}}$ decline after extended depolarization by fitting a linear function to the final $5 \mathrm{~s}$ of $C_{\mathrm{m}}$ data and subtracting the extrapolated fit. The residual was then fitted with an exponential function using a genetic curve-fitting algorithm (Sanchez del Rio and Pareschi, 2001). In a few cases, the fitting window for the linear component was slightly adjusted to exclude $C_{\mathrm{m}}$ artifacts. Recordings that could not be reliably fitted or that contained strong artifacts were discarded. All cells showed a pronounced, depolarization-independent decrease of $C_{\mathrm{m}}$ during the recording, which was corrected for by fitting and subtracting an exponen- tial function to the baseline $C_{\mathrm{m}}$ as recorded during the entire experiment (see Fig. 5). Occasional increases of baseline $C_{\mathrm{m}}$ late in the recordings were not included into the fit, because we interpret them as pathological changes reflecting lack of compensation of excessive exocytosis after $1000 \mathrm{~ms}$ depolarization or compromised cell condition.

For vglut1-pHluorin imaging, an Olympus Fluoview 300 confocal scanner mounted to a BX50WI microscope (0.9 NA, 60× waterimmersion objective; Olympus), a $50 \mathrm{~mW}, 488$ nm solid-state laser (Cyan; Newport-Spectraphysics), and a $1.5 \mathrm{~mW}, 543 \mathrm{~nm}$ helium-neon laser were used. Calibration of intravesicular $\mathrm{pH}$ was performed with extracellular solutions containing $20 \mu \mathrm{M}$ carbonyl cyanide 4-(trifluoromethoxy)phenylhydrazone (FCCP). For nonneutral solutions, the $\mathrm{pH}$ buffer HEPES was replaced with equimolar amounts of MES ( $\mathrm{pH}$ 5.5 and 6.5) or tricine ( $\mathrm{pH} 8.0$ and 9.0). Changes in vglut $1-$ pHluorin fluorescence during patchclamp recordings were monitored with $56 \times 56$ pixel (pixel size, $131 \mathrm{~nm}$ ) images acquired at 10 $\mathrm{Hz}$ (first $4 \mathrm{~s}$ ) and $2 \mathrm{~Hz}$ (after $4 \mathrm{~s}$ ). Cells were stimulated by a $100 \mathrm{~ms}$ depolarization to -17 $\mathrm{mV}$, after $1.5 \mathrm{~s}$ of baseline period. Fluorescence traces were extracted from $7 \times 7$ pixel regions of interest (ROIs) and corrected for bleaching. The bleaching rate was estimated by fitting the average fluorescence in the cytosolic region using a double-exponential function with a linear component. This function, scaled to the baseline fluorescence of each ROI, was subtracted from individual fluorescence traces to yield the $\Delta F$ trace. Analysis of electrophysiology and imaging data was performed in Igor Pro 6 software (Wavemetrics) and NIH ImageJ. Means were expressed \pm SEM and compared using Student's unpaired $t$ tests or Wilcoxon's rank tests as appropriate, with ${ }^{*} p<0.05,{ }^{*} p<0.01$, and ${ }^{* * *} p<0.001$. Average capacitance traces were filtered with a $50 \mathrm{~Hz}$ low-pass filter for better display of data.

\section{Results}

Structural correlates of endocytosis and expression of endocytic proteins in IHCs

Using electron microscopy, we observed clathrin-coated pits at the plasma membrane and clathrin-coated vesicles in the close vicinity of the IHC AZs (Fig. $1 A-C$ ). In addition, we found membrane infoldings and large cisternae most likely reflecting bulk endocytosis (Fig. 1A-D), which appeared more abundant in cells that had been stimulated with a high $\mathrm{K}^{+}$solution before fixation (Fig. 1C,D). Some of these membranous structures also showed coated parts likely indicating the clathrin-mediated budding of vesicles from the previously endocytosed cisternae. Indeed, such coats also covered aspects of membrane infoldings that still remained connected to the surface (Fig. $1 B, C$ ). Interestingly, clathrin-coated vesicles were significantly larger (average diameter, $54.2 \pm 1.0 \mathrm{~nm}$ ) than synaptic vesicles (average diameter, $30.6 \pm 0.4 \mathrm{~nm} ; p<0.001$ ), which is evident from comparing the inner diameter of both structures (Fig. 1E). The same applies to clathrin-coated pits at the plasma membrane that exhibited an average diameter of $65.1 \pm 6.6 \mathrm{~nm}$.

We then used immunohistochemistry and confocal microscopy to demonstrate the expression and subcellular distribution of dynamin(s) (Fig. 2A-C), amphiphysin (Fig. 2D), the neuronal 
splice variant of clathrin light chain (Fig. $2 E$ ), and clathrin heavy chain (Fig. $2 F$ ) in IHCs. IHCs were successfully labeled by antibodies thought to selectively recognize dynamin 1 or dynamin 3 as well as by a pan-dynamin antibody, indicating expression of dynamins 1 and 3. Knock-outcontrolled studies of dynamin expression in IHCs of hearing mice will have to await hair cell-specific deletion of dynamins. IHCs showed a broad distribution of dynamin 1 and 3, clathrin heavy chain, and weak amphiphysin immunofluorescence (Fig. 2A, $C, D, F$ ). Different from what was reported recently for retinal photoreceptors (Wahl et al., 2013), no obvious enrichment of these proteins around the ribbon-type AZ was found. Efferent (and potentially also afferent) neurons showed immunofluorescence for dynamins 1 and 3, clathrin light chain, and prominently for amphiphysin.

\section{Characterizing the use of vglut1-pHluorin for studying exocytosis and endocytosis at single IHC synapses}

We used transuterine injections of AAV into the embryonic otocyst (Bedrosian et al., 2006; Brigande et al., 2009; Reisinger et al., 2011) to express vglut1-pHluorin in IHCs. Vglut1-pHluorin was distributed throughout the IHC and overlapped with vglut3 immunofluorescence in transfected IHCs (Fig. 3A,B). IHCs showed substantial vglut1pHluorin fluorescence already at rest, which on average increased twofold on collapsing the vesicular $\mathrm{pH}$ gradient by application of $40 \mathrm{~mm}$ extracellular $\mathrm{NH}_{4} \mathrm{Cl}, \mathrm{pH}$ 7.4. This modest fluorescence gain during dequenching indicates that the intravesicular $\mathrm{pH}$ of vglut 1-pHluorin-positive IHCs is less acidic compared with that of conventional presynaptic terminals in culture $(\mathrm{pH} \sim 5.5$; Miesenböck et al., 1998), in which an $\sim 10$-fold increase in fluorescence can be observed (Miesenböck et al., 1998). To address this question further, we studied the vglut1-pHluorin fluorescence as a function of $\mathrm{pH}$ using the protonophore FCCP $(20 \mu \mathrm{M}$; Fig. $3 C, D)$. We found changes in the range of 7 - to 20 -fold between pH 5.5 and pH 9 (Fig. 3C,D), demonstrating intact vglut1pHluorin expression and function, as well as appropriate measurement conditions. Moreover, these experiments indicate that the intraluminal $\mathrm{pH}$ of vglut $1-\mathrm{pHluorin}$-positive organelles in a resting IHC is $\sim 6.5$. Given the concurrent presence of synaptic vesicle-like organelles and other intracellular membranous structures such as endocytic cisternae in the base of the IHC and the likely presence of vglut1-pHluorin in these compartments, organelles other than synaptic vesicles may contribute to the high background signal in IHCs.

Next, we combined confocal vglut1-pHluorin imaging with IHC patch clamp and marked the AZ by a ribeye-binding fluorescent peptide (Francis et al., 2011). $\mathrm{Ca}^{2+}$ influx elicited by $100-$ ms-long step depolarizations to $-17 \mathrm{mV}$ caused the appearance of significant vglut1-pHluorin fluorescence hotspots at the AZs (Fig. $4 A-C ; p<0.01$ for comparison with baseline), which was paralleled by exocytic increase of $C_{\mathrm{m}}$ (data not shown). ROIs centered on the plasma membrane away from the ribbons showed very little or no increase in fluorescence (Fig. 4A-C). The decline of synaptic vglut1-pHluorin fluorescence after exocytosis, reflecting the combination of membrane retrieval and reacidification, appeared to proceed with a fast and a slow component, similar to that observed for the endocytic $C_{\mathrm{m}}$ decay (Fig. 5B). The fluorescence decline was significant already $10 \mathrm{~s}$ after the end of the stimulus $(p<0.01)$, but additional quantification of kinetics was hampered by the relatively low signal-tonoise ratio. In conclusion, pHluorin imaging is feasible in IHCs, albeit with lower signal-to-noise ratio than described for cultured neurons, and indicated preferential occurrence of exocytosis and endocytosis at AZs in IHCs.

\section{$C_{\mathrm{m}}$ measurements reveal two kinetic components of} membrane retrieval after $\mathrm{Ca}^{2+}$ influx-triggered exocytosis We used perforated-patch recordings of IHC $C_{\mathrm{m}}$ to assess exocytosis and the time course of endocytic membrane retrieval after strong depolarization (to $-14 \mathrm{mV}$ ) for different durations. We found that brief depolarizations $(20 \mathrm{~ms}$, primarily recruiting the RRP; Moser and Beutner, 2000) mostly resulted in a slow, linear $C_{\mathrm{m}}$ decline (Fig. $5 A$; also see Figs. 7, 9, 10), whereas longer depolarizations (200 and $1000 \mathrm{~ms}$ ) additionally evoked an exponentially decaying $C_{\mathrm{m}}$ component (Fig. $5 B$; also see Figs. 6, 7, 9, 10), which became apparent when the amount of exocytosed membrane surpassed $\sim 30-40 \mathrm{fF}$, approximately three to four times the size of the RRP, and whose amplitude increased with the amount of preceding exocytosis (Fig. 5D). The time constant of the exponential $C_{\mathrm{m}}$ decline in perforated patch configuration 

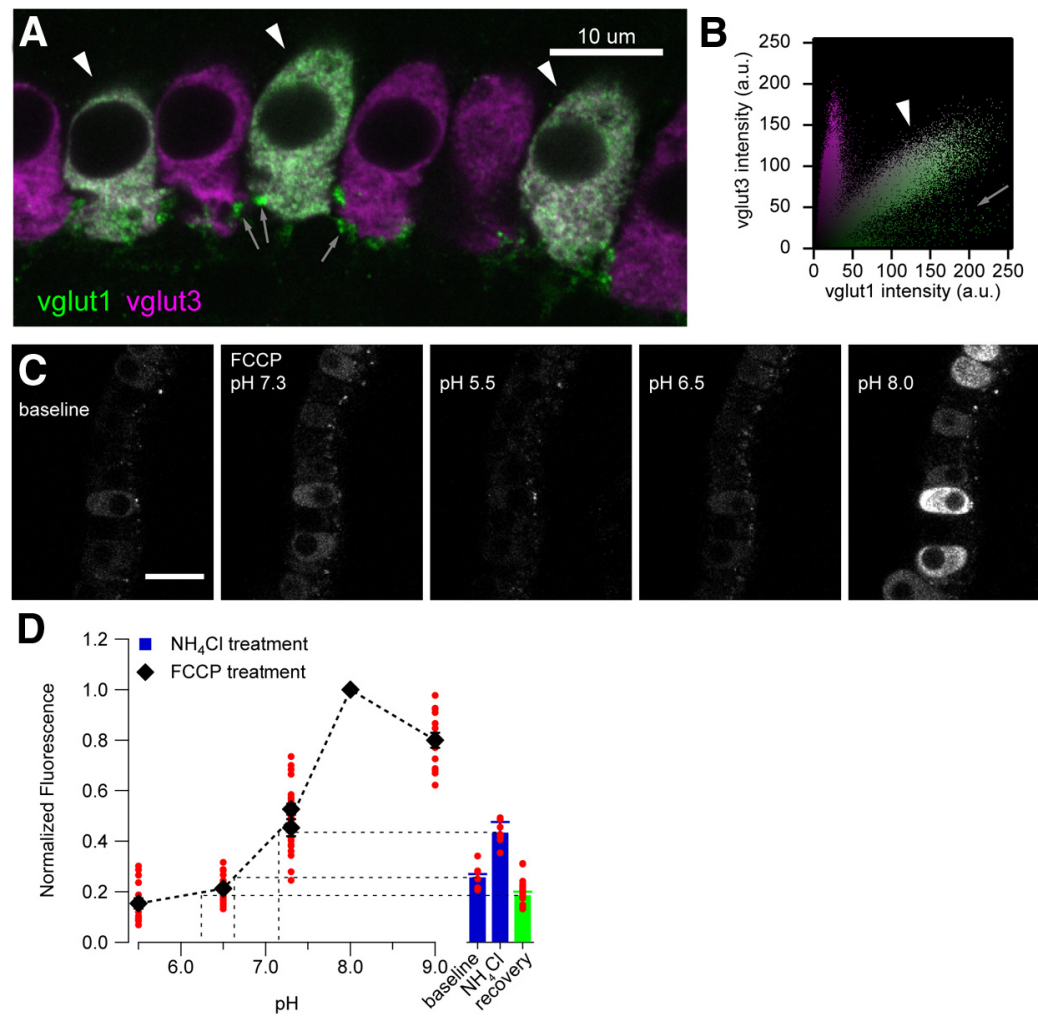

Figure 3. Expression and basic characterization of vglut1-pHluorin in IHCs. $\boldsymbol{A}$, Subcellular localization of vglut1-pHluorin highly resembles that of the endogenous vesicular glutamate transporter vglut3. Single confocal section of immunolabeled IHCS showing expression pattern of vglut1-pHluorin (labeled with anti-vglut1 antibody, green) and vglut3 (magenta). Arrowheads indicate coexpression of vglut1 and vglut3 in IHCs; arrows indicate vglut1-positive postsynaptic boutons. Scale bar, $10 \mu \mathrm{m}$. $\boldsymbol{B}$, Correlation plot of vglut1 and vglut3 immunofluorescence shows three populations: vglut1-pHluorin-transfected IHCS (arrowhead), vglut1-positive postsynaptic boutons (arrow), and nontransfected IHCs. C, Calibration of intravesicular pH using the ionophore FCCP. Confocal sections showing the fluorescence of vglut1-pHluorin-expressing IHCs in normal Ringer's solution (baseline) and when equilibrated to different pH with FCCP. Scale bar, $20 \mu \mathrm{m}$. D, Quantification of fluorescence in $\boldsymbol{C}$, showing that resting fluorescence intensity corresponds to a pH of $\sim 6.5$. The fluorescence of individual IHCs (red dots) at different pH was measured by defining an ROl encompassing the cytosolic region (excluding the nuclei) and normalized to the maximum intensity for each cell. These values are then averaged across all cells (black symbols).

averaged to $5.7 \pm 0.8 \mathrm{~s}(n=14$ IHCs $)$ and seemed primarily independent of the amount of exocytosis (Pearson's correlation coefficient of -0.09 ; and data not shown). The linear component of endocytosis was observed with similar rates also after long depolarizations, in which it was quantified by fitting a linear function to the final $5 \mathrm{~s}$ of the $C_{\mathrm{m}}$ data (Fig. $5 \mathrm{~B}$, thick gray line), indicating that this mode of endocytosis is limited in speed. Throughout these long recordings, we observed a slow $C_{\mathrm{m}}$ decline (Figs. 5C, 6A) that was also observed in the absence of stimulation and in otoferlin-deficient IHCs (data not shown), which almost completely lack depolarization-induced exocytosis (Roux et al., 2006). Possible mechanisms underlying this phenomenon include (1) an imbalance of basal exocytosis and endocytosis under these recording conditions and (2) a slow creeping up of membrane into the patch pipette attributable to capillary force. We attempted to correct for this trend in our endocytosis analysis as detailed in Materials and Methods. Recordings in the rupturedpatch configuration with $0.3 \mathrm{~mm}$ GTP in the pipette solution showed a robust endocytic $C_{\mathrm{m}}$ decline with properties that were mostly comparable with data acquired with perforated patch. Specifically, the time of return to baseline was unchanged for short depolarizations (Fig. $5 E ; 18.0 \pm 2.3$ vs $18.3 \pm 3.5 \mathrm{~s}$ in ruptured patch vs perforated patch, respectively), indicating an unaltered linear component of membrane retrieval. Likewise, the

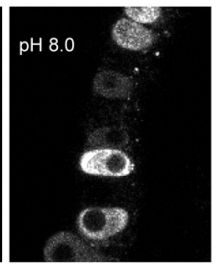

kinetics of the exponential component were comparable (Fig. $5 G$; time constant: $4.7 \pm 0.8$ vs $5.7 \pm 0.8 \mathrm{~s}$ ), whereas its amplitude was significantly increased (Fig. $5 H ; 129 \pm 20$ vs $57 \pm 18 \mathrm{fF}, p<0.01)$, suggesting a larger contribution of this component to overall retrieval.

\section{Hydrolysis of GTP is required for normal exocytosis and endocytosis in IHCs}

To determine whether global inhibition of GTP hydrolysis would block endocytic membrane retrieval as shown previously in several secretory preparations, including retinal bipolar cells (Jockusch et al., 2005) and calyx of Held (Yamashita et al., 2005), we performed ruptured-patch experiments either removing GTP from the intracellular solution or replacing it with the nonhydrolysable GTP analog GTP $\gamma \mathrm{S}$ $(0.3 \mathrm{~mm})$. We found that, in most cells, $C_{\mathrm{m}}$ increased rapidly right after infusion of GTP $\gamma S$, which strongly contrasts with the typical $C_{\mathrm{m}}$ decline observed in rupturedpatch recordings with GTP in the patch pipette (Fig. 6A) and perforated-patch experiments (see above; Fig. $5 C$ ). Only 3 of 10 IHCs infused with GTP-free intracellular solution showed a slight increase in $C_{\mathrm{m}}$. Although exocytosis triggered by $\mathrm{Ca}^{2+}$ influx is negligible at the negative holding potentials used $(-84 \mathrm{mV})$, it remains unclear whether the observed $C_{\mathrm{m}}$ rise solely reflected constitutive exocytosis not further balanced by endocytosis or also included GTP $\gamma$ S-induced exocytosis (Fernandez et al., 1984; Rupnik and Zorec, 1995). Interestingly, $\mathrm{Ca}^{2+}$ influxevoked exocytic $C_{\mathrm{m}}$ increments were reduced in amplitude in the absence of GTP and even more so in the presence of GTP $\gamma \mathrm{S}$ (Fig. $6 B$ ). Because our standard exponential fit for correcting the slow changes of baseline $C_{\mathrm{m}}$ was not applicable, we fitted a linear function to the predepolarization $C_{\mathrm{m}}$ and subtracted it from the $C_{\mathrm{m}}$ trace. The exponential component of membrane retrieval seemed somewhat slower in the absence of GTP (time constant of $8.3 \pm$ $2.2 \mathrm{~s}, p=0.16$, one recording did not show an exponential component of retrieval) and was primarily blocked in the presence of GTP $\gamma$ S (Fig. 6B). Recordings with GTP $\gamma S$ were generally less stable and often lost a few minutes after gaining access, limiting the depth of analysis.

\section{Pharmacological interference with dynamin inhibits the linear component of membrane retrieval}

In an attempt to more specifically unravel the role of dynamin in IHC endocytosis, we treated IHCs with $30 \mu \mathrm{M}$ of the dynamin inhibitor Dyngo-4a (Howes et al., 2010) or its inactive variant Dyngo-8a (Daniel et al., 2012) applied via the patch pipette in ruptured-patch experiments. We found that neither $\mathrm{Ca}^{2+}$ current amplitude (Fig. 7A) nor exocytosis of the RRP or sustained exocytosis (measured by depolarizations of 20,200 , or $1000 \mathrm{~ms}$ duration, respectively; Fig. 7A) were different between both conditions. When examining the time course of endocytic mem- 
brane retrieval, we found that the linear $C_{\mathrm{m}}$ decline after RRP exocytosis (evoked by brief depolarizations) was slowed in Dyngo-4a-treated cells $\left(C_{\mathrm{m}}\right.$ returned to baseline after $\sim 30 \mathrm{~s}$ compared with $\sim 15 \mathrm{~s}$ in Dyngo-8a-treated cells, $p<0.05$; Fig. $7 B, D)$. A trend toward slowed kinetics of the linear component of endocytosis of Dyngo-4a-treated cells was also observed in response to $200 \mathrm{~ms}$ depolarizations (Fig. 7C,E), but it did not quite reach statistical significance $(p=0.09)$. No difference was observed between both conditions for the amplitude (Fig. 7F) or the time constant (Fig. $7 G$ ) of the exponential component of the endocytic $C_{\mathrm{m}}$ decline after these prolonged depolarizations. In summary, the two kinetic modes of endocytic $C_{\mathrm{m}}$ retrieval appear to differ in their dynamin requirement.

To examine whether dynamin inhibition perhaps via a potential accumulation of vesicular membrane and proteins at the AZ membrane after repeated stimulation results in an impairment of exocytosis, we studied $\Delta C_{\mathrm{m}}$ in response to trains of $10 \times$ $1 \mathrm{~s}$ depolarizations presented at $0.7 \mathrm{~Hz}$ but found no reduction in Dyngo-4a-treated cells when compared with Dyngo-8atreated cells (Fig. 8). Instead, the slightly higher total $\Delta C_{\mathrm{m}}$ in Dyngo-4a-treated cells, not yet reaching statistical significance, potentially indicated a changed balance between exocytosis and endocytosis attributable to less efficient slow endocytosis in these cells. This suggests that the exponential component of endocytic membrane retrieval, which likely reflects bulk endocytosis and was not altered by Dyngo-4a inhibition of dynamin, provides for sufficient vesicle recycling and/or that there is a large reserve pool of synaptic vesicles that enables RRP replenishment.

\section{Genetic disruption of dynamin 1 function inhibits the linear component of membrane retrieval}

To verify the results of the pharmacological inhibition and to elucidate which dynamin isoform is involved, we turned toward studying endocytosis in IHCs of dynamin 1 mutant mice. We investigated fitful mouse mutants, carrying a point mutation in dynamin 1 that results in impaired dynamin 1 dimerization and function and causes a slight hearing deficit (Boumil et al., 2010). These mice offer the advantage that data from mature (P14-P17) IHCs can be acquired, in contrast to constitutive dynamin 1 knock-out mice that die before the onset of hearing (Ferguson et al., 2007; data not shown). In the mutant IHCs, we found unchanged $\mathrm{Ca}^{2+}$ currents and exocytosis (Fig. 9A). However, the time required for $C_{\mathrm{m}}$ to return to baseline after $20 \mathrm{~ms}$ depolarization was significantly slowed $(p<0.05$; Fig. $9 B, D)$. Conversely, endocytosis in response to prolonged depolarization appeared normal in fitful IHCs (Fig. $9 C, F, G)$, although a trend toward slower rates of the linear $C_{\mathrm{m}}$ decline was observed, which did not reach statistical significance (Fig. 9E; $p=0.41$ ). The similar effect of genetic disruption of dynamin 1 function on the linear component of endocytosis when compared with that of the pharmacological

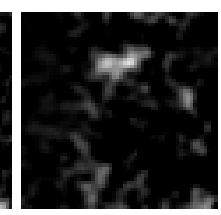

(ii) - baseline
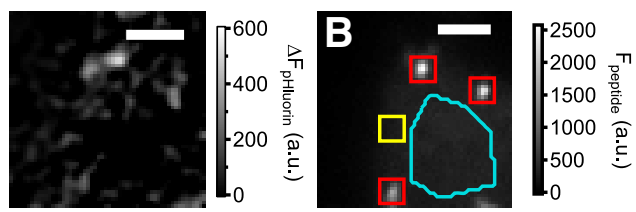

(iii) - baseline
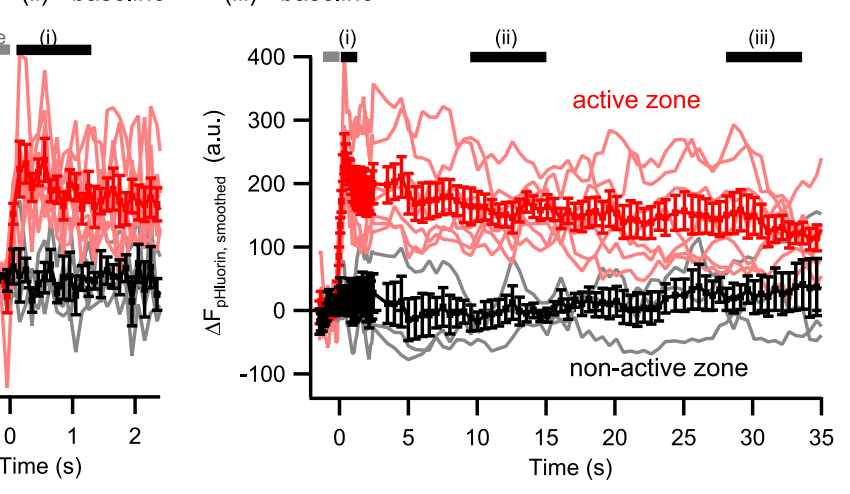

लें

$$
\text { . }
$$

Fepolarization-evoked prolonged increase in vglut1-pHluorin fluorescence at IHC AZs. $\boldsymbol{A}$, Representative example of

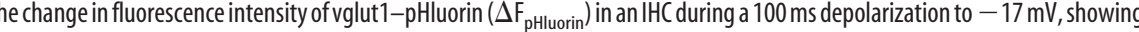

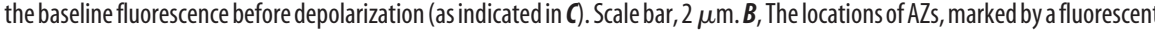
when baseline and raw images for $\boldsymbol{A}$ were acquired, respectively. Light red and gray traces represent vglut1-pHluorin fluorescence dynamin inhibition by Dyngo-4a suggests that Dyngo-4a primarily worked via inhibiting dynamin 1 .

\section{Pharmacological interference with clathrin function inhibits the linear component of membrane retrieval}

We next used pitstop 2, a clathrin inhibitor (von Kleist et al., 2011), to test the clathrin dependence of IHC endocytosis. Pitstop 2 ( $30 \mu \mathrm{M}$, diluted in $0.1 \%$ DMSO) was applied to IHCs by bath perfusion for at least $10 \mathrm{~min}$. Exocytosis and endocytosis were probed by 20-, 200-, and 1000-ms-long depolarizations to $-14 \mathrm{mV}$. Exocytic $C_{\mathrm{m}}$ changes were not significantly altered compared with control cells for any of the stimulus durations (Fig. 10A). However, the $C_{\mathrm{m}}$ return to baseline after $20 \mathrm{~ms}$ depolarization (linear component) was slowed in the presence of pitstop 2 (Fig. $10 B, D ; p<0.05$ ). Again, a nonsignificant trend toward slower rates of the linear component was observed for the $200 \mathrm{~ms}$ depolarizations in pitstop 2-treated cells (Fig. 10E; $p=$ 0.45). Conversely, the exponential component of the endocytic $C_{\mathrm{m}}$ decline in response to $200 \mathrm{~ms}$ depolarization was not affected (Fig. 10C, F, G), suggesting that this mode of membrane retrieval does not require clathrin function in IHCs. In summary, the data indicate that clathrin, as dynamin, is required for the linear component of endocytic $C_{\mathrm{m}}$ retrieval, whereas the exponential component seems independent of clathrin and dynamin 1 function.

\section{Genetic disruption of otoferlin does not interfere with rapid} endocytosis and its $\mathrm{Ca}^{2+}$ dependence

Otoferlin has been implicated in the regulation of vesicle fusion and replenishment in IHCs (Roux et al., 2006; Johnson and Chapman, 2010; Pangršič et al., 2010, 2012) and has been proposed recently to be involved in coupling exocytosis to endocytosis via its interaction with the endocytic adapter protein AP2 (Duncker et al., 2013). Analyzing endocytosis in IHCs lacking 
A

B
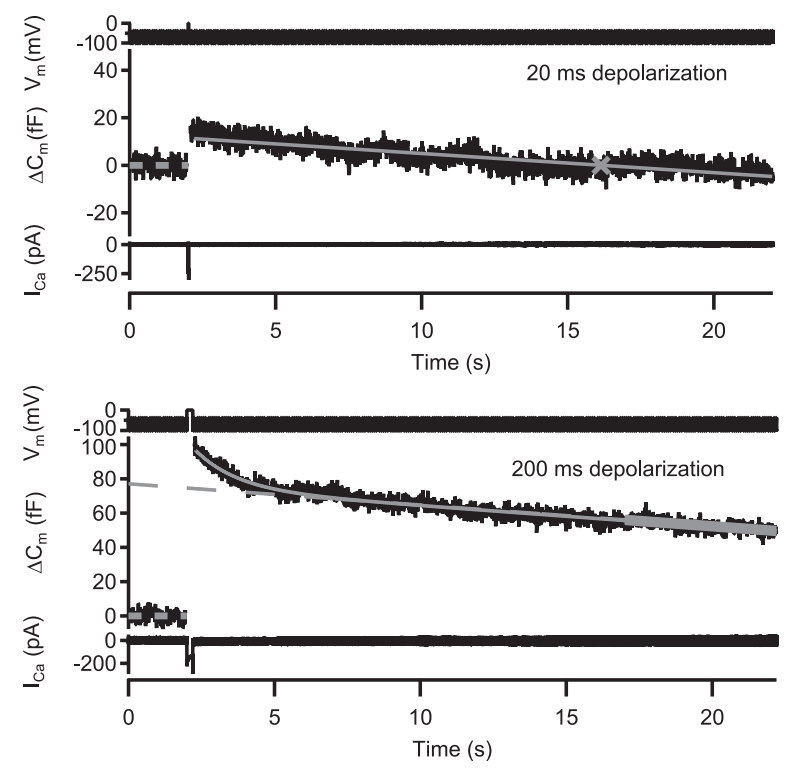

C

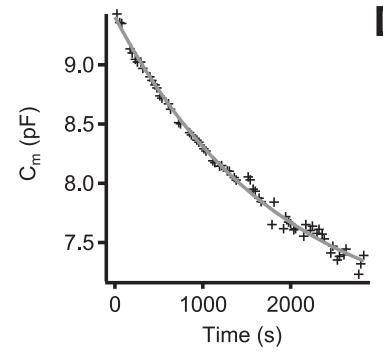

E

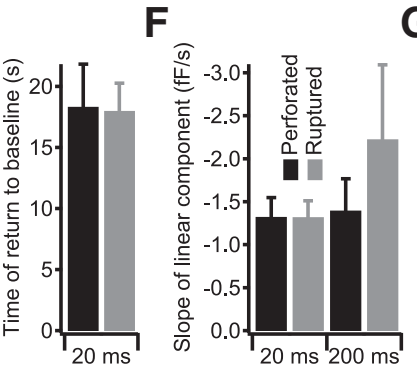

D 800 - $0200 \mathrm{~ms}$ depol.

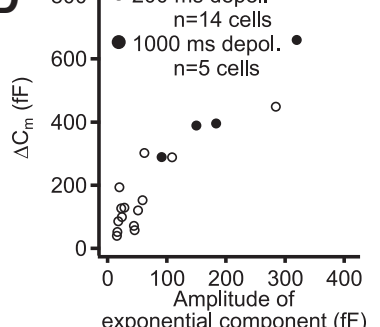

G

$\mathrm{H}$
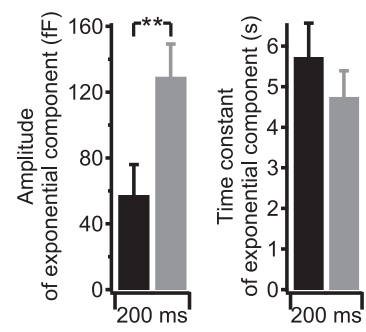

Figure 5. Endocytic $C_{m}$ decline in control IHCS. $A, B$, Representative recordings in response to 20 $(\boldsymbol{A})$ or 200 ( $B$ ) ms depolarizations. The command voltage consisted of a 2-s-long predepolarization sine wave part, the depolarizing pulse, and a 20-s-long postdepolarization sine wave part (top). After the depolarization-induced $C_{m}$ increase, the slope-corrected $C_{m}$ traces (middle) typically showed a linear decay after 20-ms-long depolarizations $(\boldsymbol{A})$, which was analyzed by subtracting the baseline $C_{m}$ (dashed bold gray line) from $0-2 \mathrm{~s}$ and fitting a linear function to the $C_{m}$ data (gray line), thus obtaining the time of return to baseline $C_{m}$ (gray mark). The 200-ms-long depolarizations typically resulted in a combination of exponential and linear decay $(\boldsymbol{B})$. This was analyzed by fitting a linear function to the final $5 \mathrm{~s}$ of $C_{m}$ data (bold gray line), which was extrapolated (dashed gray line) and subtracted from the $C_{m}$ data. The residual was fitted with an exponential function (gray line shows combined linear and exponential). $C$, Representative example of $C_{m}$ slope correction in an IHC. The correction for baseline $C_{m}$ drift was performed by monitoring the baseline $C_{m}$ during the experiment (black symbols) and fitting an exponential function (gray line), which was then subtracted from the individual recordings. $\boldsymbol{D}$, Recordings after longer depolarizations showed an exponential component whose amplitude increased with the total amount of previously exocytosed membrane. Open circles are cell averages from $200 \mathrm{~ms}$ depolarizations, and filled circles are cell averages from $1000 \mathrm{~ms}$ depolarizations. $\boldsymbol{E}-\boldsymbol{H}$, Comparison of time of return to baseline $(\boldsymbol{E})$, slope of the linear component of membrane retrieval after short (left) and prolonged (right) exocytosis $(\boldsymbol{F})$, and the amplitudes $(\boldsymbol{G})$ and time constants $(\boldsymbol{H})$ of the exponential component of membrane retrieval in from IHCs recorded in perforated-patch (black) or ruptured-patch configuration (gray). The perforated-patch data $(n=17$ and $n=14$ cells for short and prolonged depolarization, respectively) are taken from the $\mathrm{Dyn}{ }^{+/+}$ cells shown in Figure 9 , and the ruptured-patch data ( $n=18$ and $n=16$ cells for short and prolonged depolarization, respectively) are pooled from the control cells shown in Figures 7 and 10.
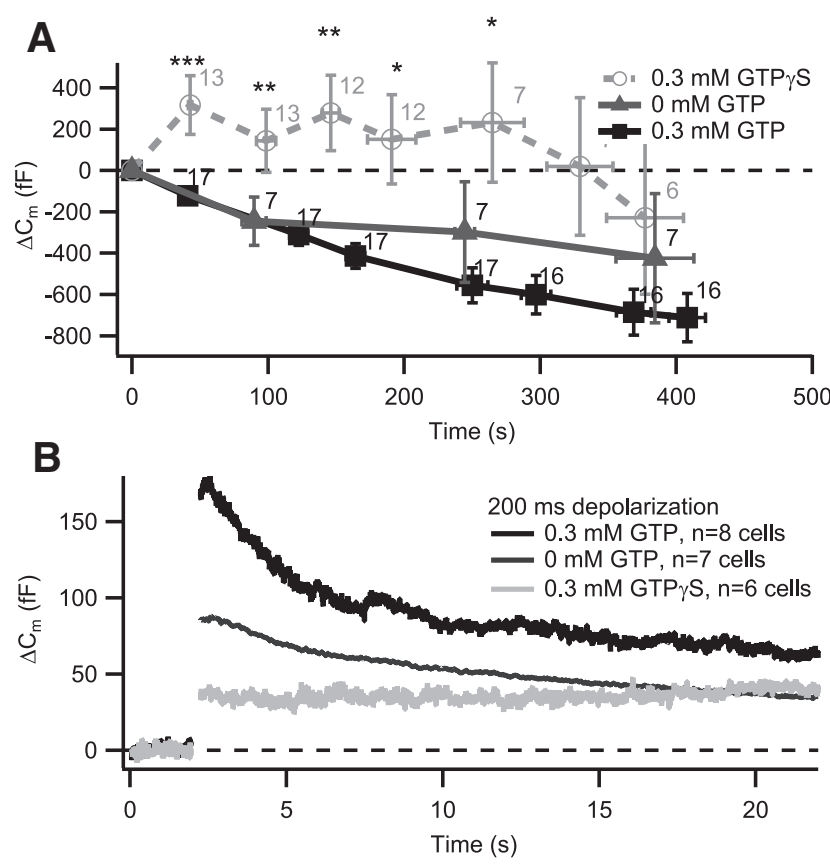

Figure 6. Hydrolysis of GTP is required for normal exocytosis and endocytosis in IHCs. IHCs in acute explants of P14-P17 organs of Corti were patch clamped in ruptured patch configuration, with either $0.3 \mathrm{~mm}$ GTP (black), $0 \mathrm{~mm}$ GTP (dark gray), or $0.3 \mathrm{~mm}$ GTP $\gamma 5$ (light gray) in the patch pipette. $A$, GTP $\gamma$-infused cells exhibit rapid increases in $C_{m}$ as opposed to the decrease found in GTP-infused cells. Bold lines represent the grand average, with the numbers at each point indicating the number of cells used in the average. $C_{m}$ was monitored by repetitive 2-s-long recordings, of which the average is displayed. Most ( 9 of 13) cells treated with GTP $\gamma 5$ showed a continuous $C_{m}$ increase in membrane surface, whereas two showed a rapid $C_{m}$ increase, followed by a $C_{m}$ decline and another two showed a continuous $C_{m}$ decline over the entire experiment. All control cells showed a continuous decline over the entire experiment. Some ( 3 of 10 ) cells infused with a GTP-free intracellular solution showed a slight increase of $C_{m}$, one showed constant $C_{m}$, and the rest showed a continuous decline over the entire experiment. $\boldsymbol{B}$, Average $\Delta C_{\mathrm{m}}$ responses of the IHCs to $200 \mathrm{~ms}$ depolarizations to $-14 \mathrm{mV}$ in the presence of $0.3 \mathrm{~mm}$ GTP $\gamma S$ (light gray), 0 mм GTP (dark gray), or $0.3 \mathrm{~mm}$ GTP (black). Infusion of GTP $\gamma S$ blocks endocytosis and also reduces the amount of exocytosis, whereas lack of GTP leads to reduced exocytosis and a trend toward slower endocytosis (time constant of $8.3 \pm 2.2 \mathrm{~s}$ without GTP vs $4.6 \pm 1.1$ with GTP, $p=0.16$, one GTP-free recording did not show an exponential component of retrieval).

otoferlin is hampered by the strong reduction of $\mathrm{Ca}^{2+}$-triggered exocytosis. However, otoferlin-deficient IHCs display reduced but still sizable exocytosis and endocytosis in response to $\mathrm{Ca}^{2+}$ uncaging (Roux et al., 2006), whereby a quantitative analysis of endocytosis remained to be performed. Here, we analyzed the kinetics and $\mathrm{Ca}^{2+}$ dependence of rapid endocytosis in IHCs lacking otoferlin (Otof ${ }^{-1-}$; Roux et al., 2006; Pangršič et al., 2010; Reisinger et al., 2011). Figure $11 \mathrm{~A}$ displays the average $C_{\mathrm{m}}$ responses of $\mathrm{Otof}^{+/+}$and Otof ${ }^{-1-}$ IHCs, pooling new results with previously published data (Roux et al., 2006; Pangršič et al., 2010). In line with strongly reduced exocytosis in Otof ${ }^{-1-}$, we found much lower maximal rates of endocytosis (Fig. $11 B-D$ ). The kinetics of rapid endocytosis (Fig. $11 F$ ) and its contribution to membrane retrieval (Fig. $11 B, C, E$ ) were similar between IHCs of the different genotypes. Moreover, as reported for wild-type IHCs (Beutner et al., 2001), the kinetics of rapid endocytosis seemed primarily independent of the $\left[\mathrm{Ca}^{2+}\right]$ achieved by $\mathrm{Ca}^{2+}$ uncaging (Fig. $11 F$ ). In conclusion, these data suggest that the lack of otoferlin does not disrupt the rapid mode of endocytosis in IHCs. 

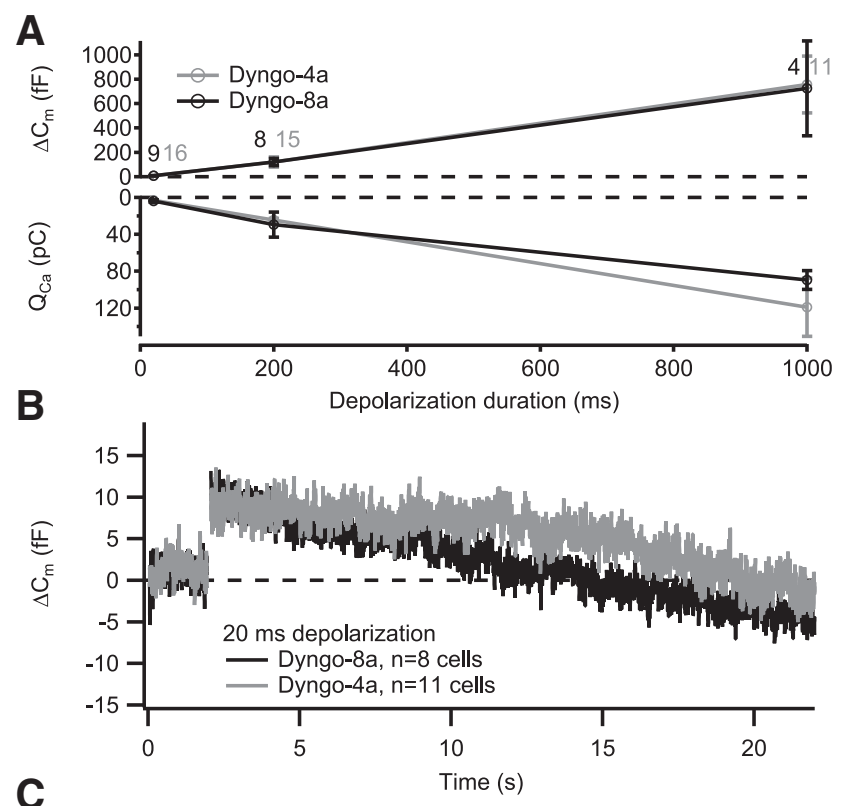

C
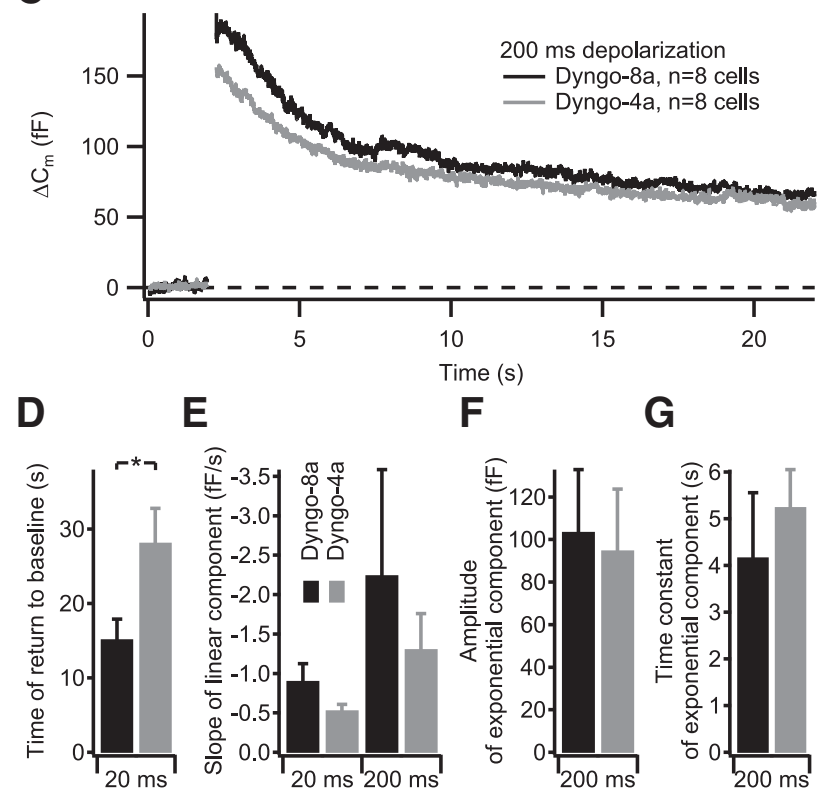

Figure 7. The dynamin inhibitor Dyngo-4a impairs the linear mode of membrane retrieval. IHCs in acute explants of P14-P17 organs of Corti were patch clamped in ruptured-patch configuration. $A$, Grand average of depolarization-evoked exocytic $\Delta C_{m}$ (top) and integrated $C^{2}{ }^{2+}$ influx (bottom) of IHCs treated with $30 \mu \mathrm{M}$ of the dynamin inhibitor Dyngo-4a (gray) or its inactive variant Dyngo-8a (black), applied via the patch pipette. The numbers at each point indicate the number of cells used for the average. $B, C$, Grand average of $\Delta C_{m}$ measurements using $20 \mathrm{~ms}(\boldsymbol{B})$ or $200 \mathrm{~ms}(\boldsymbol{C})$ depolarizing stimuli from IHCs treated with Dyngo-4a (gray) or Dyngo-8a (black). $\boldsymbol{D}$, Average time of $C_{\mathrm{m}}$ return to baseline obtained from fitting a linear function to the first $20 \mathrm{~s}$ of $C_{m}$ data after the end of the $20 \mathrm{~ms}$ depolarizing pulses summarized in $\boldsymbol{B}$. $\boldsymbol{E}$, Average slope of the linear component of exocytosis for $20 \mathrm{~ms}$ depolarizing pulses (left, obtained by fitting a linear function to the first $20 \mathrm{~s}$ of postdepolarization $C_{\mathrm{m}}$ data) and $200 \mathrm{~ms}$ depolarizing pulses (right, obtained by fitting a linear function to the final $5 \mathrm{~s}$ of $C_{\mathrm{m}}$ data). $\boldsymbol{F}, \mathbf{G}$, Average amplitudes $(\boldsymbol{F})$ and time constants $(\boldsymbol{G})$ of exponential functions fitted to the data summarized in $C$ after subtracting the linear decrease in $C_{m}$ during the final $5 \mathrm{~s}$ of the recording.

\section{Discussion}

Here we characterized three kinetic modes of endocytic membrane retrieval in mouse IHCs and provide first insight into their molecular regulation. We present evidence for a slow clathrinand dynamin 1-dependent mode of membrane retrieval. It apparently proceeds with a limited and nearly constant rate and

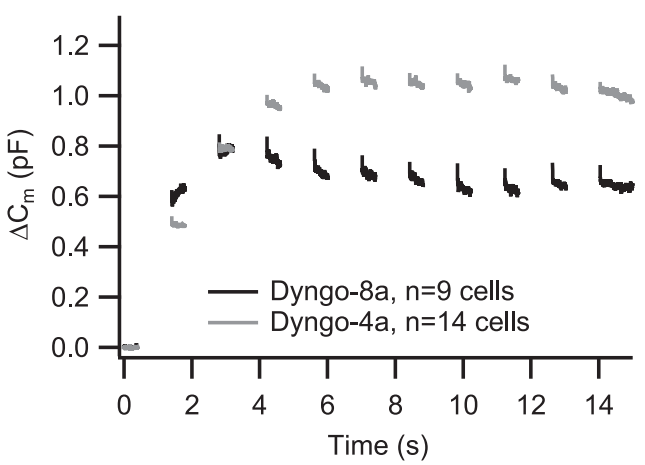

Figure 8. Prolonged exocytosis appears normal in Dyngo-4a-treated cells. IHCs in acute explants of P14-P17 organs of Corti were patch clamped in ruptured-patch configuration and exposed to trains of $10 \times 1 \mathrm{~s}$ depolarizations to $-14 \mathrm{mV}$ at $0.7 \mathrm{~Hz}$. Interpulse interval was 200 ms. No significant difference could be observed between cells treated with Dyngo-4a ( $g r a y$ ) and Dyngo-8a (black) in the cumulative exocytic $\Delta C_{\mathrm{m}}$.

probably represents CME. $\mathrm{Ca}^{2+}$ influx-triggered exocytosis exceeding approximately three to four equivalents of the RRP increasingly recruits an additional exponential component of membrane retrieval. It proceeds with a time constant of $\sim 6 \mathrm{~s}$, seems to be clathrin and dynamin independent, and probably represents bulk endocytosis. Rapid endocytosis (time constant of $\sim 250 \mathrm{~ms}$ ) after global $\left[\mathrm{Ca}^{2+}\right]$ elevation to $15 \mu \mathrm{M}$ or more seemed mostly unaffected by otoferlin disruption and, because of its speed, may reflect kiss-and-run endocytosis. Finally, we characterized vglut $1-\mathrm{pHluorin}$ imaging for studying exocytosis and endocytosis in IHCs and indicate local membrane cycling.

\section{Insights into IHC endocytosis from $C_{\mathrm{m}}$ and pHluorin recordings}

Analysis of hair cell endocytosis by $C_{\mathrm{m}}$ measurements and optical methods (Gale et al., 2001; Griesinger et al., 2002; Granseth et al., 2006; the present study) requires consideration of potential caveats. First, whole-cell $C_{\mathrm{m}}$ measurements lack spatial resolution and report the sum of exocytic membrane fusion and endocytic membrane fission. Finding that vglut1-pHluorin fluorescence primarily increases at ribbon-type AZs (Fig. 4) argues that $\mathrm{Ca}^{2+}$ influx-triggered exocytosis preferentially occurs synaptically, which is consistent with other lines of evidence (Griesinger et al., 2005; Schnee et al., 2005; Goutman and Glowatzki, 2007; Li et al., 2009; Meyer et al., 2009). vglut1-pHluorin fluorescence remained near the AZs for several seconds, which seems hard to reconcile with a vivid diffusion of exocytosed membrane and proteins to the apical pole of the hair cell for endocytosis (Griesinger et al., 2005). Therefore, we favor the hypothesis of a local recycling of synaptic vesicle membrane and proteins, which is further supported by parallel work using a novel fluorescent membrane tracer (N. H. Revelo, D. Kamin, A. B. Wong, K. Reuter, E. Reisinger, T. Moser, and S. O. Rizzoli, unpublished observations).

Second, the $C_{\mathrm{m}}$ decline reports the reduction of membrane accessible to voltage clamp. However, we cannot rule out that membrane infoldings that remained connected to the extracellular space via narrow membrane necks or even fission pores escaped the voltage clamp and were mistaken as completely retrieved. This could explain why pitstop 2 and Dyngo-4a apparently had no effect on the exponential component of the $C_{\mathrm{m}}$ decline, whereby the GTP $\gamma \mathrm{S}$ effect might then be attributed to continued G-protein-driven asynchronous exocytosis (Fernan- 


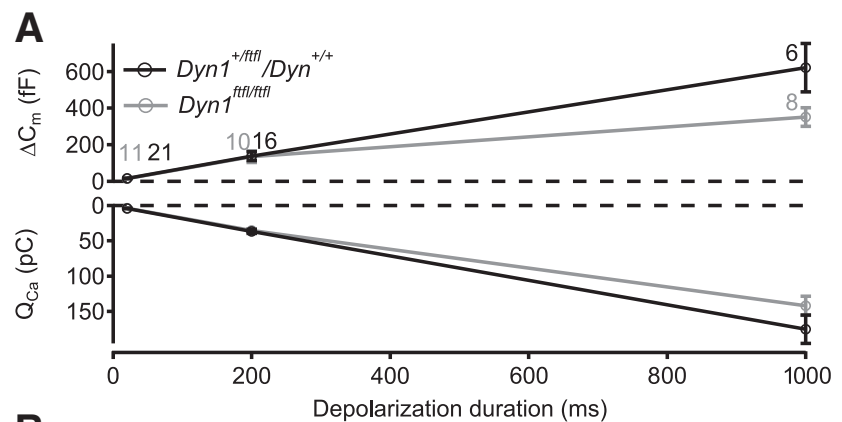

B
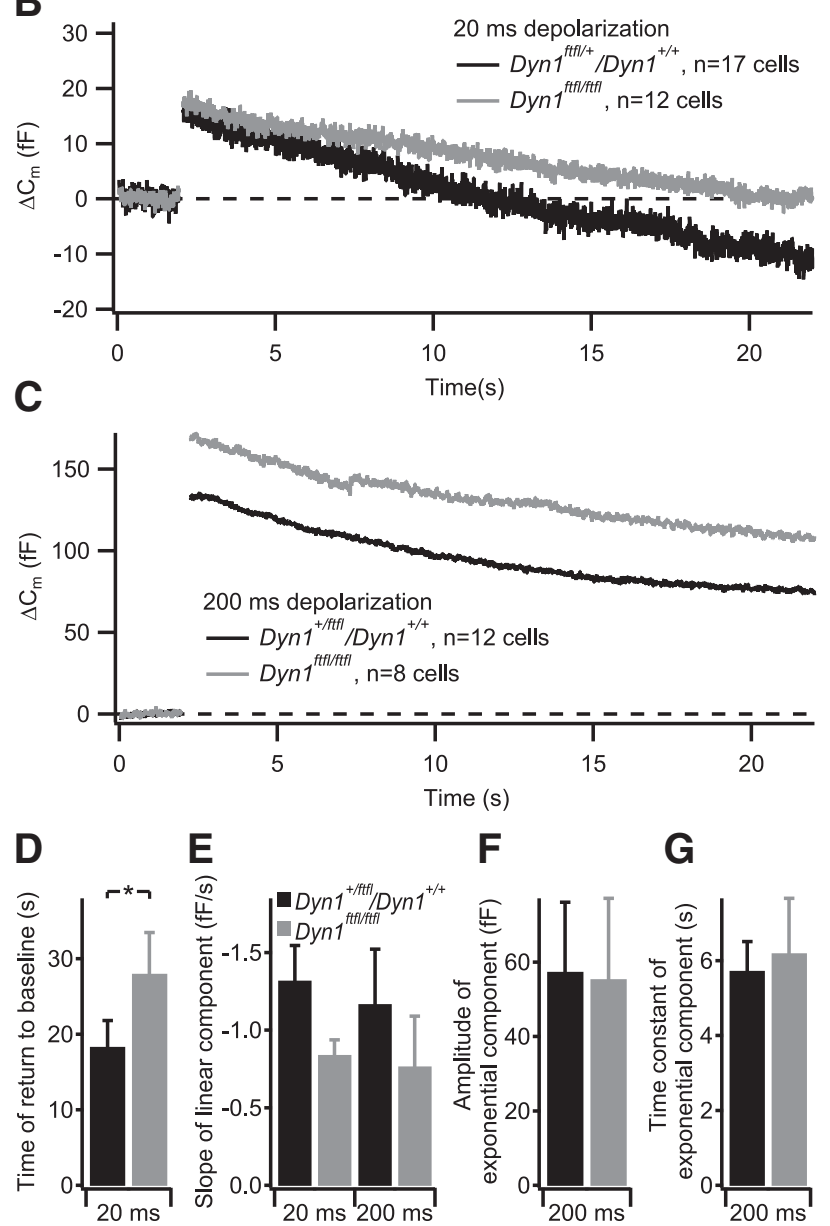

Figure 9. The fitful mutation of dynamin 1 impairs the linear component of membrane retrieval. IHCs in acute explants of P14-P17 organs of Corti were patch clamped in perforatedpatch configuration. $A$, Grand average of depolarization-evoked exocytic $\Delta C_{m}$ (top) and integrated $\mathrm{Ca}^{2+}$ influx (bottom) of IHCs from Dyn $7^{\text {ftfl/fftl }}$ (gray) or littermate Dyn $7^{\text {ftfl/++}}$ or Dyn $1^{+/+}$ mice (black). The numbers at each point indicate the number of cells used for the average. $B, C$, Grand average of $\Delta C_{\mathrm{m}}$ measurements using $20 \mathrm{~ms}(\boldsymbol{B})$ or $200 \mathrm{~ms}(\boldsymbol{C})$ depolarizing stimuli. $\boldsymbol{D}$, Average time of $C_{m}$ return to baseline obtained from fitting a linear function to the first $20 \mathrm{~s}$ of $C_{m}$ data after the end of the $20 \mathrm{~ms}$ depolarizing pulses summarized in $\boldsymbol{B}$. $\boldsymbol{E}$, Average slope of the linear component of exocytosis for $20 \mathrm{~ms}$ depolarizing pulses (left, obtained by fitting a linear function to the first $20 \mathrm{~s}$ of postdepolarization $C_{m}$ data) and $200 \mathrm{~ms}$ depolarizing pulses (right, obtained by fitting a linear function to the final $5 \mathrm{~s}$ of $\boldsymbol{C}_{\mathrm{m}}$ data). $\boldsymbol{F}, \boldsymbol{G}$, Average amplitudes $(\boldsymbol{F})$ and time constants $(\boldsymbol{G})$ of exponential functions fitted to the data summarized in $\boldsymbol{C}$ after subtracting the linear decrease in $C_{m}$ during the final $5 \mathrm{~s}$ of the recording.

dez et al., 1984; Rupnik and Zorec, 1995), balancing the extent of membrane infolding in a quantitative manner. Alternatively, the discrepancy between the effects of Dyngo-4a and GTP $\gamma S$ might be explained by the inhibition of activity of dynamin 3 by GTP $\gamma S$ but not Dyngo-4a. Third, using vglutl rather than the physiologically expressed vglut3 for pHluorin imaging may have altered
A

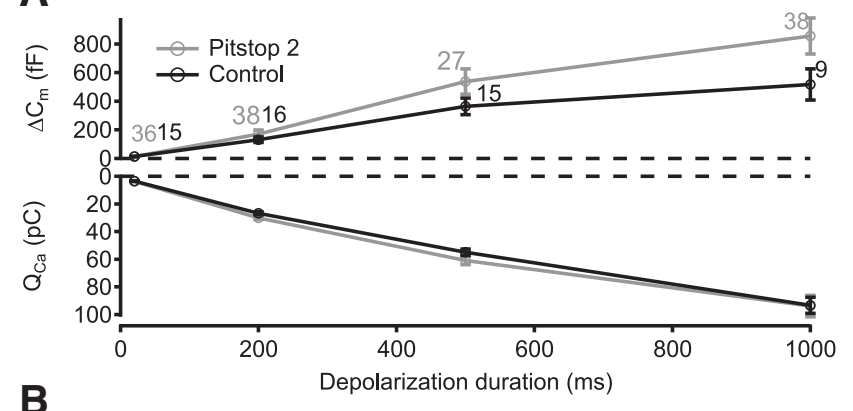

B
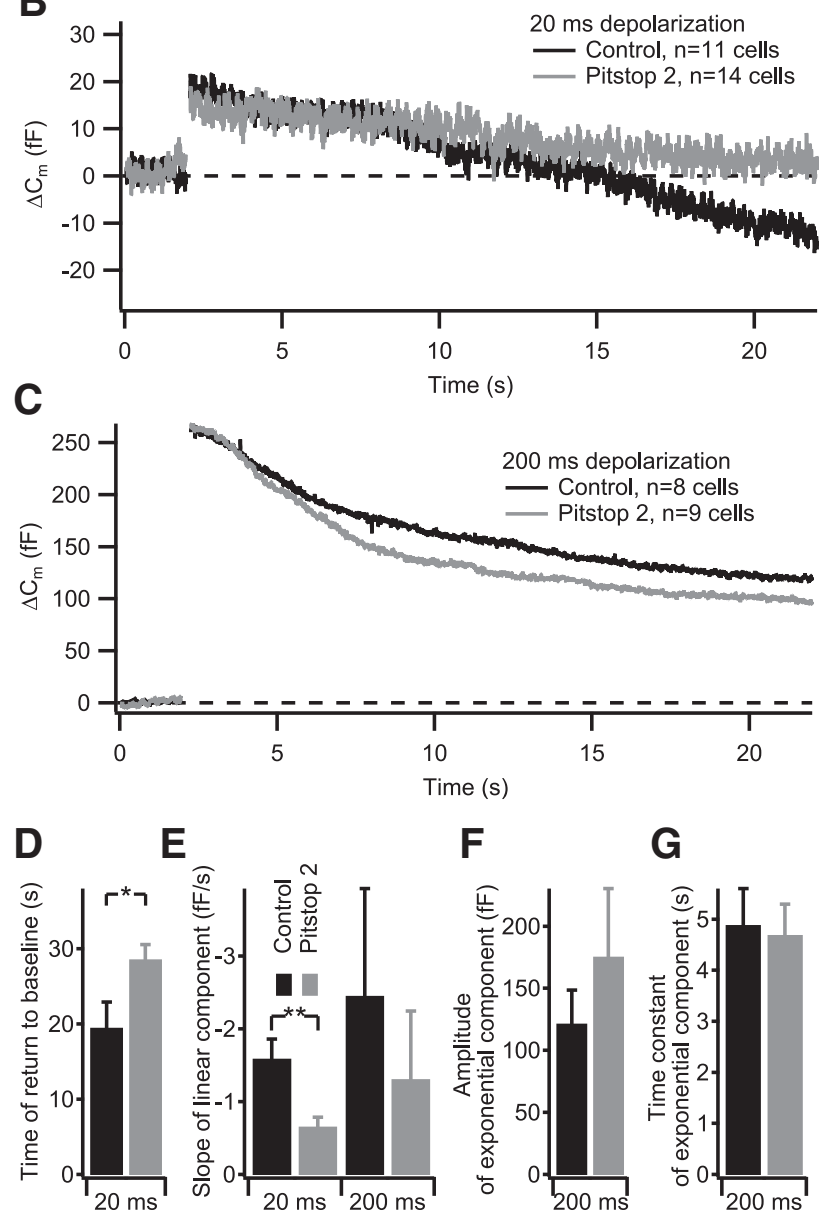

G

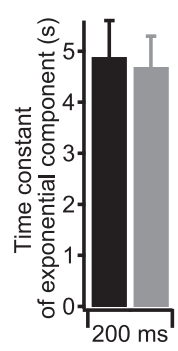

Figure 10. The clathrin inhibitor pitstop 2 blocks the linear component of membrane retrieval. IHCs in acute explants of P14-P17 organs of Corti were patch clamped in perforatedpatch configuration. $A$, Grand average of depolarization-evoked exocytic $\Delta C_{\mathrm{m}}$ (top) and integrated $\mathrm{Ca}^{2+}$ influx (bottom) of IHCs treated with $30 \mu \mathrm{m}$ pitstop 2 (gray) or control cells (black). The numbers at each point indicate the number of cells used for the average. $B, C$, Grand average of $\Delta C_{\mathrm{m}}$ measurements using $20 \mathrm{~ms}(\boldsymbol{B})$ or $200 \mathrm{~ms}(\boldsymbol{C})$ depolarizing stimuli. $\boldsymbol{D}$, Average time of $C_{m}$ return to baseline obtained from fitting a linear function to the first $20 \mathrm{~s}$ of $C_{m}$ data after the end of the $20 \mathrm{~ms}$ depolarizing pulses summarized in $\boldsymbol{B}$. $\boldsymbol{E}$, Average slope of the linear component of exocytosis for $20 \mathrm{~ms}$ depolarizing pulses (left, obtained by fitting a linear function to the first $20 \mathrm{~s}$ of postdepolarization $C_{\mathrm{m}}$ data) and $200 \mathrm{~ms}$ depolarizing pulses (right, obtained by fitting a linear function to the final $5 \mathrm{~s}$ of $\boldsymbol{C}_{\mathrm{m}}$ data). $\boldsymbol{F}, \boldsymbol{G}$, Average amplitudes $(\boldsymbol{F})$ and time constants $(\boldsymbol{G})$ of exponential functions fitted to the data summarized in $\boldsymbol{C}$ after subtracting the linear decrease in $C_{m}$ during the final $5 \mathrm{~s}$ of the recording.

vesicular function, and future experiments using vglut3-pHluorin will be useful. Fourth, exocytosis and endocytosis are strongly influenced by temperature (Nouvian, 2007; Renden and von Gersdorff, 2007). It is possible that results obtained at physiological temperature differ from those presented here. Our data show that, contrary to a previous report (Parsons et al., 1994), endo- 
A
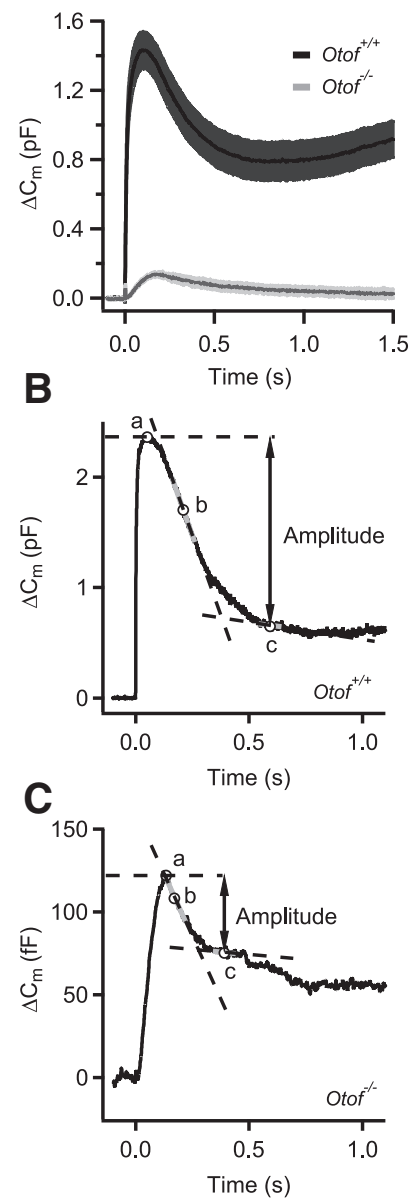
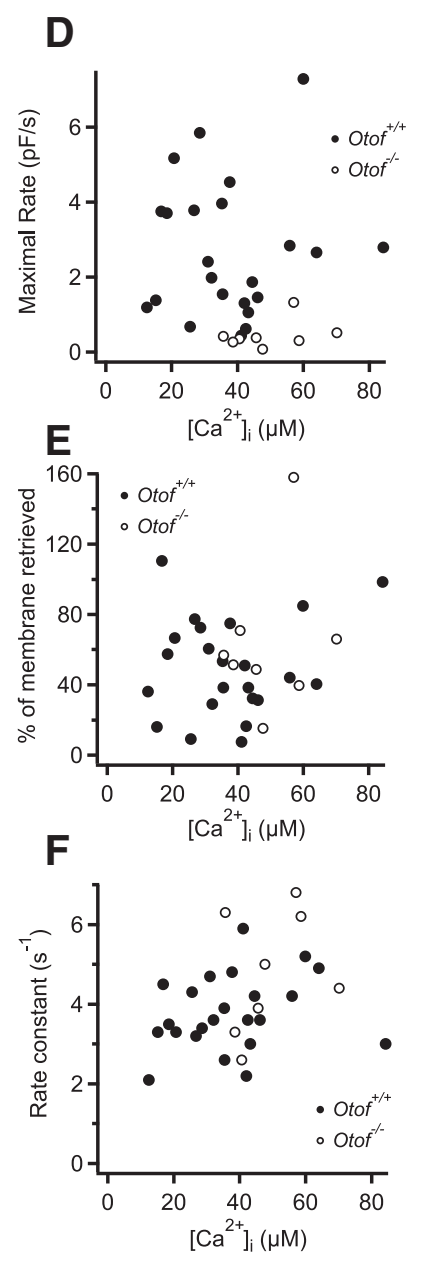

Figure 11. Rapid endocytic $C_{m}$ decline after flash photolysis is primarily unaffected by otoferlin disruption. $A$, Average flash photolysis-evoked $\Delta C_{\mathrm{m}}$ responses in IHCs of wild-type (Otof $^{+/+}$, black) and otoferlin knock-out (Otof ${ }^{-1-}$, gray) mice. UV $\mathrm{Ca}^{2+}$ uncaging was triggered at time point $0 . \boldsymbol{B}, \boldsymbol{C}$, Examples of a flash response in a wild-type $(\boldsymbol{B})$ and otoferlin knock-out (C) IHC. Maximal rate of endocytosis was determined by fitting a line (dotted lines) to overlapping $100 \mathrm{~ms}$ segments of the $C_{\mathrm{m}}$ trace and finding the one with the most negative slope (at point b). The amplitude of endocytosis was then defined as the $C_{m}$ difference between the point of maximal $C_{m}$ response (point a) and the point at which the endocytic rate fell to $5 \%$ of the maximal rate (at point c). D, Maximal rate of endocytosis in 0 tof ${ }^{+/+}$(filled circles) and Otof ${ }^{-1-}$ (open circles) IHCs as a function of peak postflash $\left[\mathrm{Ca}^{2+}\right]_{\mathrm{i}}$. Slow and small exocytosis in Otof ${ }^{-1-}$ IHCs was followed by endocytosis at lower rates. $E$, Percentage of exocytosed membrane that is retrieved until the rate of endocytosis is reduced to $5 \%$ of the maximal rate [see $\boldsymbol{B}$ and $\boldsymbol{C}$ : (point a - point c)/point a $\times 100$ ]. $\boldsymbol{F}$, The rate constant of endocytosis, obtained by dividing maximal endocytic rate by the amplitude of endocytosis, as a function of peak postflash $\left[\mathrm{Ca}^{2+}\right]_{\mathrm{i}}$. Endocytic rate constants that are independent of postflash $\left[\mathrm{Ca}^{2+}\right]_{\mathrm{i}}$ were not significantly different between the two genotypes (Student's $t$ test, $p=0.1$ ).

cytic membrane retrieval in hair cells can also be measured in ruptured-patch configuration, which likely relates to GTP being present in the intracellular solution in our experiments (Fig. 6) but not in the study by Parsons et al. (1994).

IHCs uses a rate-limited clathrin- and dynamin-dependent membrane retrieval that balances exocytosis at low rates of stimulation

Regardless of the amount of preceding exocytosis, we observed a linear decline of $C_{\mathrm{m}}$ that proceeded with a rate of $\sim 1-2 \mathrm{fF} / \mathrm{s}$, which corresponds to the retrieval of approximately two to four synaptic vesicle equivalents ( $45 \mathrm{aF}$; Neef et al., 2007) per synapse and second. Inhibition of clathrin by pitstop 2 as well as block of

dynamin by Dyngo-4a $\left(\mathrm{IC}_{50}\right.$ for dynamin 1 of $0.4 \mu \mathrm{M}$; Daniel et al., 2012), but not its inactive control Dyngo-8a ( IC $_{50}$ for dynamin 1 of $47 \mu \mathrm{M}$; Daniel et al., 2012), inhibited this mode of membrane retrieval, indicating that it represents dynamindependent CME. Moreover, this component of $C_{\mathrm{m}}$ decline was also inhibited by a missense mutation in dynamin 1 ( fitful) that we showed previously to interfere with dynamin 1 dimerization and to cause a mild hearing impairment (Boumil et al., 2010). Because the effects of the fitful mutation and of Dyngo-4a, which at concentration used ( $30 \mu \mathrm{M}$, applied via the patch pipette) likely blocks dynamin 1 and 2, were comparable, we suggest that dynamin 1 is the prevailing dynamin isoform mediating membrane fission during the linear component of $C_{\mathrm{m}}$ decline in IHCs of hearing mice. Although interference with dynamin and clathrin function did not reach significance for endocytosis after $200 \mathrm{~ms}$ stimuli, we assume that the substantial variability of the $C_{\mathrm{m}}$ decline masked the inhibition of the linear component of $C_{\mathrm{m}}$ decline. This slow mode of IHC endocytosis is reminiscent of the slow mode of endocytosis in goldfish retinal bipolar neurons for its clathrin and dynamin dependence (Jockusch et al., 2005). However, different from these ribbon synapses and the calyx of Held, which use a fast exponential mechanism of limited capacity to retrieve membrane after brief $\mathrm{Ca}^{2+}$ influx (Sun et al., 2002; Wu et al., 2005; Yamashita et al., 2005; Renden and von Gersdorff, 2007; Lou et al., 2008; Llobet et al., 2011), IHCs use this slow mode for compensating low rates of exocytosis.

The exponential component of $C_{\mathrm{m}}$ decline increases with the amount of exocytosis and likely represents bulk endocytosis When the amount of exocytosis exceeded approximately three to four RRP equivalents, IHCs recruited a second, exponentially decaying component of $C_{\mathrm{m}}$ decline. This component increased in amplitude with the amount of preceding exocytosis (Fig. 5D) but the decay time constant was nearly constant, contrasting with reports from frog auditory hair cells in which the time constant scaled with preceding release (Cho et al., 2011). This component might represent bulk endocytosis (for review, see Clayton and Cousin, 2009), used in addition to the slower clathrin-dependent mode of membrane retrieval when a certain threshold of exocytosis or accumulated $\mathrm{Ca}^{2+}$ charge is passed. Indeed, there is good evidence for bulk endocytosis at ribbon synapses in general (Holt et al., 2003; Paillart et al., 2003; Coggins et al., 2007) and also at hair cell synapses (Fig. 1; Lenzi et al., 2002). However, different from bipolar cells (von Gersdorff and Matthews, 1994; Neves and Lagnado, 1999; Llobet et al., 2011), its contribution seems to increase with the amount of preceding exocytosis in IHCs (Fig. $5 D$ ). We postulate that IHCs use bulk endocytosis as a mechanism to increase the surface on which the endocytic machinery can operate to recycle vesicles, while maintaining the perisynaptic plasma membrane organization during strong exocytic load. This view is supported by the presence of cisternal membrane organelles around the AZ, which exceed the size of coated vesicles but in many cases show a clathrin coat on some part of the membrane (Fig. $1 A, D$ ). It will be interesting to test whether, as for bulk endocytosis in CNS terminals, this mode of endocytosis is regulated by $\mathrm{Ca}^{2+}$ and calcineurin (Clayton et al., 2009; Wu et al., 2009; Yamashita et al., 2010). However, CME seems not to immediately recycle synaptic vesicles either, because clathrin-coated vesicles are approximately twofold larger than synaptic vesicles in IHCs (Fig. 1E). 


\section{Coupling of exocytosis and endocytosis in IHCs}

Coupling of exocytosis and endocytosis is probably critical in IHCs, given their high sustained release rates (hundreds of $\mathrm{Hz}$; Frank et al., 2010; Pangršič et al., 2010, 2012), and its regulation may involve otoferlin (Duncker et al., 2013), which is required for efficient vesicle replenishment (Pangršič et al., 2010). Therefore, we revisited the question whether absence of otoferlin disrupts endocytic membrane retrieval and tested the impact of inhibiting endocytosis on exocytosis (Kawasaki et al., 2000; Hosoi et al., 2009). We quantified rapid endocytosis occurring after $\mathrm{Ca}^{2+}$ uncaging in IHCs of otoferlin knock-out mice (Roux et al., 2006; Reisinger et al., 2011) and found comparable time constants and contributions. This argues against an essential role of otoferlin in regulating this mode of hair cell endocytosis. Moreover, we did not observe a significant reduction of exocytosis with any of the manipulations that selectively impeded the linear component of endocytosis. This is different from the calyx of Held synapse, in which inhibited AZ clearance has been implicated to explain the slowing of vesicle replenishment during manipulation of endocytosis (Hosoi et al., 2009; Xu et al., 2013). However, even when massively driving exocytosis by repetitive stimulation with strong stimuli, which turned over membrane equivalent to $>10 \%$ of the IHC plasma membrane, we did not find a reduction with Dyngo$4 \mathrm{a}$, contrasting a recent report that Dynasore, another dynamin inhibitor, inhibits exocytosis (Duncker et al., 2013). The lack of a reduction of exocytosis in the presence of Dyngo-4a in our study despite $\sim 100$ RRP equivalents turned over ( $1 \mathrm{pF}$ cumulative $C_{\mathrm{m}}$ rise, RRP of $\sim 10 \mathrm{fF}$; Pangršič et al., 2010) argues against a rate limitation of AZ clearance attributable to inhibition of the linear component of endocytosis. However, we cannot rule out that a complete block of endocytosis may limit exocytosis via this mechanism.

\section{Notes}

Supplemental material for this article is available at www.innerearlab. uni-goettingen.de/materials.html. The material supplies alternative versions of the figures with additional display of the SEM of the average capacitance traces. This material has not been peer reviewed.

\section{References}

Bedrosian JC, Gratton MA, Brigande JV, Tang W, Landau J, Bennett J (2006) In vivo delivery of recombinant viruses to the fetal murine cochlea: transduction characteristics and long-term effects on auditory function. Mol Ther 14:328-335. CrossRef Medline

Beutner D, Voets T, Neher E, Moser T (2001) Calcium dependence of exocytosis and endocytosis at the cochlear inner hair cell afferent synapse. Neuron 29:681-690. CrossRef Medline

Boumil RM, Letts VA, Roberts MC, Lenz C, Mahaffey CL, Zhang ZW, Moser T, Frankel WN (2010) A missense mutation in a highly conserved alternate exon of dynamin-1 causes epilepsy in fitful mice. PLoS Genet 6:pii: e1001046. CrossRef Medline

Brigande JV, Gubbels SP, Woessner DW, Jungwirth JJ, Bresee CS (2009) Electroporation-mediated gene transfer to the developing mouse inner ear. Methods Mol Biol 493:125-139. CrossRef Medline

Cho S, Li GL, von Gersdorff H (2011) Recovery from short-term depression and facilitation is ultrafast and $\mathrm{Ca}^{2+}$ dependent at auditory hair cell synapses. J Neurosci 31:5682-5692. CrossRef Medline

Clayton EL, Cousin MA (2009) The molecular physiology of activitydependent bulk endocytosis of synaptic vesicles. J Neurochem 111:901914. CrossRef Medline

Clayton EL, Anggono V, Smillie KJ, Chau N, Robinson PJ, Cousin MA (2009) The phospho-dependent dynamin-syndapin interaction triggers activity-dependent bulk endocytosis of synaptic vesicles. J Neurosci 29: 7706-7717. CrossRef Medline

Coggins MR, Grabner CP, Almers W, Zenisek D (2007) Stimulated exocytosis of endosomes in goldfish retinal bipolar neurons. J Physiol 584:853865. CrossRef Medline
Cui G, Meyer AC, Calin-Jageman I, Neef J, Haeseleer F, Moser T, Lee A (2007) $\mathrm{Ca}^{2+}$-binding proteins tune $\mathrm{Ca}^{2+}$-feedback to Cavl. 3 channels in mouse auditory hair cells. J Physiol 585:791-803. CrossRef Medline

Daniel JA, Malladi CS, Kettle E, McCluskey A, Robinson PJ (2012) Analysis of synaptic vesicle endocytosis in synaptosomes by high-content screening. Nat Protoc 7:1439-1455. CrossRef Medline

Dittman J, Ryan TA (2009) Molecular circuitry of endocytosis at nerve terminals. Annu Rev Cell Dev Biol 25:133-160. CrossRef Medline

Duncker SV, Franz C, Kuhn S, Schulte U, Campanelli D, Brandt N, Hirt B, Fakler B, Blin N, Ruth P, Engel J, Marcotti W, Zimmermann U, Knipper M (2013) Otoferlin couples to clathrin-mediated endocytosis in mature cochlear inner hair cells. J Neurosci 33:9508-9519. CrossRef Medline

Ferguson SM, De Camilli P (2012) Dynamin, a membrane-remodelling GTPase. Nat Rev Mol Cell Biol 13:75-88. CrossRef Medline

Ferguson SM, Brasnjo G, Hayashi M, Wölfel M, Collesi C, Giovedi S, Raimondi A, Gong LW, Ariel P, Paradise S, O’Toole E, Flavell R, Cremona O, Miesenböck G, Ryan TA, De Camilli P (2007) A selective activitydependent requirement for dynamin 1 in synaptic vesicle endocytosis. Science 316:570-574. CrossRef Medline

Fernandez JM, Neher E, Gomperts BD (1984) Capacitance measurements reveal stepwise fusion events in degranulating mast cells. Nature 312:453455. CrossRef Medline

Francis AA, Mehta B, Zenisek D (2011) Development of new peptide-based tools for studying synaptic ribbon function. J Neurophysiol 106:10281037. CrossRef Medline

Frank T, Rutherford MA, Strenzke N, Neef A, Pangršič T, Khimich D, Fejtova A, Gundelfinger ED, Liberman MC, Harke B, Bryan KE, Lee A, Egner A, Riedel D, Moser T (2010) Bassoon and the synaptic ribbon organize $\mathrm{Ca}^{2+}$ channels and vesicles to add release sites and promote refilling. Neuron 68:724-738. CrossRef Medline

Gale JE, Marcotti W, Kennedy HJ, Kros CJ, Richardson GP (2001) FM1-43 dye behaves as a permeant blocker of the hair-cell mechanotransducer channel. J Neurosci 21:7013-7025. Medline

Glowatzki E, Grant L, Fuchs P (2008) Hair cell afferent synapses. Curr Opin Neurobiol 18:389-395. CrossRef Medline

Goutman JD, Glowatzki E (2007) Time course and calcium dependence of transmitter release at a single ribbon synapse. Proc Natl Acad Sci U S A 104:16341-16346. CrossRef Medline

Granseth B, Odermatt B, Royle SJ, Lagnado L (2006) Clathrin-mediated endocytosis is the dominant mechanism of vesicle retrieval at hippocampal synapses. Neuron 51:773-786. CrossRef Medline

Griesinger CB, Richards CD, Ashmore JF (2002) FM1-43 reveals membrane recycling in adult inner hair cells of the mammalian cochlea. J Neurosci 22:3939-3952. Medline

Griesinger CB, Richards CD, Ashmore JF (2005) Fast vesicle replenishment allows indefatigable signalling at the first auditory synapse. Nature 435: 212-215. CrossRef Medline

Holt M, Cooke A, Wu MM, Lagnado L (2003) Bulk membrane retrieval in the synaptic terminal of retinal bipolar cells. J Neurosci 23:1329-1339. Medline

Hosoi N, Holt M, Sakaba T (2009) Calcium dependence of exo- and endocytotic coupling at a glutamatergic synapse. Neuron 63:216-229. CrossRef Medline

Howes MT, Kirkham M, Riches J, Cortese K, Walser PJ, Simpson F, Hill MM, Jones A, Lundmark R, Lindsay MR, Hernandez-Deviez DJ, Hadzic G, McCluskey A, Bashir R, Liu L, Pilch P, McMahon H, Robinson PJ, Hancock JF, Mayor S, Parton RG (2010) Clathrin-independent carriers form a high capacity endocytic sorting system at the leading edge of migrating cells. J Cell Biol 190:675-691. CrossRef Medline

Jockusch WJ, Praefcke GJK, McMahon HT, Lagnado L (2005) Clathrindependent and clathrin-independent retrieval of synaptic vesicles in retinal bipolar cells. Neuron 46:869-878. CrossRef Medline

Johnson CP, Chapman ER (2010) Otoferlin is a calcium sensor that directly regulates SNARE-mediated membrane fusion. J Cell Biol 191:187-197. CrossRef Medline

Kawasaki F, Hazen M, Ordway RW (2000) Fast synaptic fatigue in shibire mutants reveals a rapid requirement for dynamin in synaptic vesicle membrane trafficking. Nat Neurosci 3:859-860. CrossRef Medline

Kügler S, Hahnewald R, Garrido M, Reiss J (2007) Long-term rescue of a lethal inherited disease by adeno-associated virus-mediated gene transfer in a mouse model of molybdenum-cofactor deficiency. Am J Hum Genet 80:291-297. CrossRef Medline 
Lenzi D, Crum J, Ellisman MH, Roberts WM (2002) Depolarization redistributes synaptic membrane and creates a gradient of vesicles on the synaptic body at a ribbon synapse. Neuron 36:649-659. CrossRef Medline

Levic S, Bouleau Y, Dulon D (2011) Developmental acquisition of a rapid calcium-regulated vesicle supply allows sustained high rates of exocytosis in auditory hair cells. PLoS One 6:e25714. CrossRef Medline

Li GL, Keen E, Andor-Ardó D, Hudspeth AJ, von Gersdorff H (2009) The unitary event underlying multiquantal EPSCs at a hair cell's ribbon synapse. J Neurosci 29:7558-7568. CrossRef Medline

Lindau M, Neher E (1988) Patch-clamp techniques for time-resolved capacitance measurements in single cells. Pflugers Arch 411:137-146. CrossRef Medline

Llobet A, Gallop JL, Burden JJE, Camdere G, Chandra P, Vallis Y, Hopkins CR, Lagnado L, McMahon HT (2011) Endophilin drives the fast mode of vesicle retrieval in a ribbon synapse. J Neurosci 31:8512-8519. CrossRef Medline

Lou X, Paradise S, Ferguson SM, De Camilli P (2008) Selective saturation of slow endocytosis at a giant glutamatergic central synapse lacking dynamin 1. Proc Natl Acad Sci U S A 105:17555-17560. CrossRef Medline

Meyer AC, Moser T (2010) Structure and function of cochlear afferent innervation. Curr Opin Otolaryngol Head Neck Surg 18:441-446. CrossRef Medline

Meyer AC, Frank T, Khimich D, Hoch G, Riedel D, Chapochnikov NM, Yarin YM, Harke B, Hell SW, Egner A, Moser T (2009) Tuning of synapse number, structure and function in the cochlea. Nat Neurosci 12:444-453. CrossRef Medline

Miesenböck G, De Angelis DA, Rothman JE (1998) Visualizing secretion and synaptic transmission with $\mathrm{pH}$-sensitive green fluorescent proteins. Nature 394:192-195. CrossRef Medline

Moser T, Beutner D (2000) Kinetics of exocytosis and endocytosis at the cochlear inner hair cell afferent synapse of the mouse. Proc Natl Acad Sci U S A 97:883-888. CrossRef Medline

Neef A, Khimich D, Pirih P, Riedel D, Wolf F, Moser T (2007) Probing the mechanism of exocytosis at the hair cell ribbon synapse. J Neurosci 27: 12933-12944. CrossRef Medline

Neher E, Sakaba T (2008) Multiple roles of calcium ions in the regulation of neurotransmitter release. Neuron 59:861-872. CrossRef Medline

Neves G, Lagnado L (1999) The kinetics of exocytosis and endocytosis in the synaptic terminal of goldfish retinal bipolar cells. J Physiol 515:181-202. CrossRef Medline

Nouvian R (2007) Temperature enhances exocytosis efficiency at the mouse inner hair cell ribbon synapse. J Physiol 584:535-542. CrossRef Medline

Paillart C, Li J, Matthews G, Sterling P (2003) Endocytosis and vesicle recycling at a ribbon synapse. J Neurosci 23:4092-4099. Medline

Pangršič T, Lasarow L, Reuter K, Takago H, Schwander M, Riedel D, Frank T, Tarantino LM, Bailey JS, Strenzke N, Brose N, Müller U, Reisinger E, Moser T (2010) Hearing requires otoferlin-dependent efficient replenishment of synaptic vesicles in hair cells. Nat Neurosci 13:869-876. CrossRef Medline

Pangršič T, Reisinger E, Moser T (2012) Otoferlin: a multi-C2 domain protein essential for hearing. Trends Neurosci 35:671-680. CrossRef Medline

Parsons TD, Lenzi D, Almers W, Roberts WM (1994) Calcium-triggered exocytosis and endocytosis in an isolated presynaptic cell: capacitance measurements in saccular hair cells. Neuron 13:875-883. CrossRef Medline

Reisinger E, Bresee C, Neef J, Nair R, Reuter K, Bulankina A, Nouvian R, Koch M, Bückers J, Kastrup L, Roux I, Petit C, Hell SW, Brose N, Rhee JS, Kügler S, Brigande JV, Moser T (2011) Probing the functional equivalence of otoferlin and synaptotagmin 1 in exocytosis. J Neurosci 31:48864895. CrossRef Medline

Renden R, von Gersdorff H (2007) Synaptic vesicle endocytosis at a CNS nerve terminal: faster kinetics at physiological temperatures and increased endocytotic capacity during maturation. J Neurophysiol 98:3349-3359. CrossRef Medline

Roux I, Safieddine S, Nouvian R, Grati M, Simmler MC, Bahloul A, Perfettini I, Le Gall M, Rostaing P, Hamard G, Triller A, Avan P, Moser T, Petit C (2006) Otoferlin, defective in a human deafness form, is essential for exocytosis at the auditory ribbon synapse. Cell 127:277-289. CrossRef Medline

Royle SJ, Lagnado L (2010) Clathrin-mediated endocytosis at the synaptic terminal: bridging the gap between physiology and molecules. Traffic 11:1489-1497. CrossRef Medline

Rupnik M, Zorec R (1995) Intracellular Cl- modulates $\mathrm{Ca}^{2+}$-induced exocytosis from rat melanotrophs through GTP-binding proteins. Pflugers Arch 431:76-83. CrossRef Medline

Rutherford MA, Chapochnikov NM, Moser T (2012) Spike encoding of neurotransmitter release timing by spiral ganglion neurons of the cochlea. J Neurosci 32:4773-4789. CrossRef Medline

Sanchez del Rio M, Pareschi G (2001) Global optimization and reflectivity data fitting for $\mathrm{x}$-ray multilayer mirrors by means of genetic algorithms. SPIE Proceedings 88-96.

Schnee ME, Ricci AJ (2003) Biophysical and pharmacological characterization of voltage-gated calcium currents in turtle auditory hair cells. J Physiol 549:697-717. CrossRef Medline

Schnee ME, Lawton DM, Furness DN, Benke TA, Ricci AJ (2005) Auditory hair cell-afferent fiber synapses are specialized to operate at their best frequencies. Neuron 47:243-254. CrossRef Medline

Sendin G, Bulankina AV, Riedel D, Moser T (2007) Maturation of ribbon synapses in hair cells is driven by thyroid hormone. J Neurosci 27:31633173. CrossRef Medline

Siegel JH (1992) Spontaneous synaptic potentials from afferent terminals in the guinea pig cochlea. Hear Res 59:85-92. CrossRef Medline

Siegel JH, Brownell WE (1986) Synaptic and Golgi membrane recycling in cochlear hair cells. J Neurocytol 15:311-328. CrossRef Medline

Smith SM, Renden R, von Gersdorff H (2008) Synaptic vesicle endocytosis: fast and slow modes of membrane retrieval. Trends Neurosci 31:559-568. CrossRef Medline

Sun JY, Wu XS, Wu LG (2002) Single and multiple vesicle fusion induce different rates of endocytosis at a central synapse. Nature 417:555-559. CrossRef Medline

Trapani JG, Obholzer N, Mo W, Brockerhoff SE, Nicolson T (2009) synaptojanin 1 is required for temporal fidelity of synaptic transmission in hair cells. PLoS Genet 5:e1000480. CrossRef Medline

von Gersdorff H, Matthews G (1994) Inhibition of endocytosis by elevated internal calcium in a synaptic terminal. Nature 370:652-655. CrossRef Medline

von Kleist L, Stahlschmidt W, Bulut H, Gromova K, Puchkov D, Robertson MJ, MacGregor KA, Tomlin N, Pechstein A, Chau N, Chircop M, Sakoff J, von Kries JP, Saenger W, Kräusslich HG, Shupliakov O, Robinson PJ, McCluskey A, Haucke V (2011) Role of the clathrin terminal domain in regulating coated pit dynamics revealed by small molecule inhibition. Cell 146:471-484. CrossRef Medline

Wahl S, Katiyar R, Schmitz F (2013) A local, periactive zone endocytic machinery at photoreceptor synapses in close vicinity to synaptic ribbons. J Neurosci 33:10278-10300. CrossRef Medline

Wu LG (2004) Kinetic regulation of vesicle endocytosis at synapses. Trends Neurosci 27:548-554. CrossRef Medline

Wu LG, Ryan TA, Lagnado L (2007) Modes of vesicle retrieval at ribbon synapses, calyx-type synapses, and small central synapses. J Neurosci 27 : 11793-11802. CrossRef Medline

Wu W, Xu J, Wu XS, Wu LG (2005) Activity-dependent acceleration of endocytosis at a central synapse. J Neurosci 25:11676-11683. CrossRef Medline

Wu XS, McNeil BD, Xu J, Fan J, Xue L, Melicoff E, Adachi R, Bai L, Wu LG (2009) $\mathrm{Ca}^{2+}$ and calmodulin initiate all forms of endocytosis during depolarization at a nerve terminal. Nat Neurosci 12:1003-1010. CrossRef Medline

Xu J, Luo F, Zhang Z, Xue L, Wu XS, Chiang HC, Shin W, Wu LG (2013) SNARE proteins synaptobrevin, SNAP-25, and syntaxin are involved in rapid and slow endocytosis at synapses. Cell Rep 3:1414-1421. CrossRef Medline

Yamashita T, Hige T, Takahashi T (2005) Vesicle endocytosis requires dynamin-dependent GTP hydrolysis at a fast CNS synapse. Science 307: 124-127. Medline

Yamashita T, Eguchi K, Saitoh N, von Gersdorff H, Takahashi T (2010) Developmental shift to a mechanism of synaptic vesicle endocytosis requiring nanodomain $\mathrm{Ca}^{2+}$. Nat Neurosci 13:838-844. CrossRef Medline

Yang PS, Alseikhan BA, Hiel H, Grant L, Mori MX, Yang W, Fuchs PA, Yue DT (2006) Switching of $\mathrm{Ca}^{2+}$-dependent inactivation of $\mathrm{Ca}(\mathrm{v}) 1.3 \mathrm{chan}$ nels by calcium binding proteins of auditory hair cells. J Neurosci 26: 10677-10689. CrossRef Medline 